\title{
Amino acid-based surfactants: New antimicrobial agents
}
A. Pinazo $^{1}$, M.A. Manresa ${ }^{2}$, A.M. Marques ${ }^{2}$, M. Bustelo ${ }^{1}$, M.J. Espuny ${ }^{2}$, L. Pérez ${ }^{1 *}$
${ }^{1}$ Department of Chemical and Surfactant Technology, IQAC, CSIC, C/JordiGirona 18- 26, 08034, Barcelona, Spain
${ }^{2}$ Departament of Microbiology, Facultat de Farmàcia, Universitat de Barcelona, Av. Joan XIII s/n, 08028, Barcelona, Spain

*Corresponding author:

Lourdes Pérez Muñoz

Fax: (+33) 34932045904

E-mail: lourdes.perez@cid.csic.es 


\begin{abstract}
The rapid increase of drug resistant bacterial makes necessary the development of new antimicrobial agents. Synthetic amino acid-based surfactants constitute a promising alternative to conventional antimicrobial compounds given that they can be prepared from renewable raw materials. In this review, we discuss the structural features that promote antimicrobial activity of amino acid-based surfactants. Monocatenary, dicatenary and gemini surfactants that contain different amino acids on the polar head and show activity against bacteria are revised. The synthesis and basic physico-chemical properties has also been included
\end{abstract}

\title{
Keywords:
}

Amino acid-based surfactants, Antimicrobial activity, Mode of action, Aggregation, Cytotoxicity 


\section{CONTENTS}

1. Introduction

2. Structure, synthesis and properties of antimicrobial amino acid-based surfactants

2.1.Single chain surfactants with one amino acid

2.1.1. Arginine

2.1.2. Lysine

2.1.3. Other amino acids

2.2.Single chain surfactants with two or more amino acids on the polar head

\subsection{Double chain surfactants}

2.3.1. Glycerolipidic structures

2.3.2. Double chain surfactants from lysine

2.3.3. Gemini surfactants

3. Other applications

4. Conclusions

5. Acknowledgements

6. References 


\section{Introduction}

The rapid increase of multiple drug resistant bacteria and fungi poses a serious threat to society [1]. For example, in the United States and the United Kingdom, 40-60\% of nosocomial Staphylococcus aureus strains are methicillin-resistant (MRSA) [2] and more deaths are associated with MRSA than with methicillin-sensitive strains [3]. Therefore, there is an urgent necessity to design new antimicrobial compounds that impede the development of acquired resistance. One possible strategy is the preparation of compounds with novel modes of action and different targets compared to existing antibiotics.

Cationic antimicrobial peptides (AMPs) are emerging as potent antimicrobial agents. Produced by all types of living organisms, AMPs are key components of the innate immune system and are active against invading pathogens, including bacteria, fungi and yeast [4]. These antimicrobials consist of 12-50 amino acids that show a net positive charge at physiological $\mathrm{pH}$ and a hydrophobic bulk. An optimal association between the cationic charge and the hydrophobic part of the molecule was found to be crucial for the antimicrobial activity of these compounds [5]. Importantly, AMPs usually work through relatively non-specific modes of action, in contrast with conventional antibiotics, which target specific enzymes or DNA. Instead of targeting a single molecule or process, they associate with cellular membranes, resulting in depolarization, lysis, and cell death, probably due to their successful incorporation into the hydrophobic lipid bilayer [6]. This hampers the development of bacterial resistance against their activity. However, in spite of the excellent antimicrobial performance of AMPs, there are some drawbacks in their application [7]: a) their chemical synthesis entails a high production cost, b) linear peptides are often easily proteolytically degraded, and c) they are not generally cellspecific and are also toxic to mammalian cells.

Native lipopeptides composed of an aliphatic acid attached to a short peptide portion of six or seven amino acids are also effective antimicrobial agents. Like AMPS, they act via perturbation of the bacterial membrane [8], and have the same disadvantage in that they are toxic to mammalian cells due to a lack of selectivity [9].

Classic cationic surfactants derived from quaternary ammonium groups are also applied for their antimicrobial properties [10]. In fact, these surfactants have been used for well 
over half a century as antiseptics together with products such as dressing, catheters and sutures. By reducing hospital infections, cationic antimicrobials diminish the need for antibiotics, which has had a positive impact on antibiotic resistance development. Moreover, despite their widespread usage, no apparent reduction in their effectiveness has been observed. Nevertheless, they are not suitable for biomedical applications due to their haemolytic activity and cytotoxicity [11]. Their use is also seriously questioned from an environmental point of view as they are not readily biodegradable and are toxic to aquatic organisms [12]. Insufficient biodegradation of chemical compounds increases their toxicity, given that aquatic organisms have more time in contact with them. Laboratory studies have shown that dimethyldidecyl ammonium chloride is hydrolytically stable and resistant to microbial degradation and the predicted half-lives in aquatic environments are equal to or longer than 3 years [13].

Nowadays, synthetic cationic amino acid-based surfactants are being explored as promising alternatives to conventional antimicrobial agents. Structurally, these compounds can be considered as analogues of native lipopeptides since they are cationic amphiphiles consisting of one or two amino acids linked to a hydrophobic moiety. They therefore share the same mode of action against microorganisms and low susceptibility to inducing resistance.

The interaction of cationic amphiphiles with microorganisms involves two main steps. Firstly, the amphiphile becomes attached to the target membrane, a process governed by electrostatic interactions between the positively charged polar head of the surfactants and the negatively charged molecules of the bacterial membranes (lipopolysaccharides in Gram-negative and lipoteichoic acid in Gram-positive bacteria) [14]. These electrostatic interactions are also entropically favored due to the release of counterions. Subsequently, the hydrophobic alkyl chain of cationic amphiphiles interacts with the lipid bilayers of membranes, modifying the membrane architecture and promoting the transport of intracellular constituents across the cell membranes [15]. In this second step, an optimum relationship between the hydrophobicity and polarity of the surfactant is necessary to facilitate the diffusion of the surfactant in the non-polar environment of lipid bilayers. This mechanism explains the activity of cationic surfactants, generally more potent against Gram-positive bacteria, which contain high amounts of negatively charged lipids. Most of them do not show antifungal activity because the negative 
charge density at the cell membrane in these microorganisms is lower than in bacteria [16].

The high number of different types of amino acids, as well as their diverse nature (polar, non polar, acidic, basic), allows a wide range of cationic amphiphile structures with diversified specifications to be designed. Furthermore, given their simple structure, consisting of one or two amino acids linked to an aliphatic chain, their synthesis does not involve many steps. Consequently, their manufacturing cost is economically viable and they can be prepared in accordance with the current environmental regulations (use of renewable starting materials with a low volume of hazardous solvents). In general, these kinds of surfactants can be considered as readily biodegradable compounds. One of the major advantages of antimicrobial amino-acid surfactants is their double functionality: as well as featuring the typical properties of surface active molecules (forming molecular aggregates as micelles or vesicles and thereby reducing surface tension), they can also act as antimicrobial agents.

\section{Structure, synthesis and properties of antimicrobial amino acid-based surfactants}

\subsection{Single chain surfactants with one amino acid}

Amino acid-based surfactants constitute an interesting alternative to conventional synthetic surfactants, bearing some of the fundamental requirements for industrial development: (a) multifunctionality, (b) low toxicity, (c) renewable sources of raw materials, (d) biodegradability and (e) simple synthesis.

Amino acids have at least two functional groups, the carboxylic group and the amino group. These compounds can be easily converted to single chain surfactants with a reactive molecule bearing a hydrophobic chain, such as fatty acids, fatty esters, fatty amines and fatty alcohols. The hydrophobic chain can be introduced into the amino acid structure through ester alkyl or amide linkages (Figure 1).

Amino acids with reactive side chains such as lysine or arginine offer additional opportunities for the molecular design of monocatenary surfactants. From an economical and environmental point of view, single chain surfactants with only one amino acid on the polar head are highly attractive compounds, since they can be easily prepared. 


\subsubsection{Arginine}

Due to the presence of a guanidine group, the arginine amino acid is an excellent raw material to prepare surfactants with antimicrobial activity. The literature describes a significant number of compounds with excellent antiseptic and pharmacological behaviour whose common feature is strongly basic groups of the guanidine type attached to a fairly large lipophilic molecule [17]. Our group has developed different synthetic routes (chemical, enzymatic or a combination of both methodologies) to prepare a wide range of single chain arginine structures (Figure 2) [18].

Long chain $\mathrm{N}^{\alpha}$-acyl arginine methyl or ethyl ester surfactants (Figure 2, series 1) were synthesized by the condensation of one hydrophobic group to the $\alpha$-amino group of the arginine methyl or ethyl ester. The guanidine side chain of arginine is an extremely strong base, which in an unsubstituted state remains protonated under normal conditions for $\alpha$-acylation [19]. It is therefore possible to work with an unprotected arginine side chain by carefully controlling the $\mathrm{pH}$, and dicyclohexyl carbodiimide can be used to condense the fatty acid [20]. This method allowed the use of very mild experimental conditions, thereby avoiding racemization and the formation of undesirable by-products. The long fatty acyl chain can also be introduced with the corresponding acid chloride by using a mixture of water/acetone as the solvent or only water [21].

Arginine-n-alkyl amide dihydrochlorides (Figure 2, series 2) and arginine-O-alkyl ester dihydrochlorides (Figure 2, series 3) contain two positively charged groups in the polar head, one in the primary amine and the second in the guanidine function. Series 2 was first prepared by chemical procedures involving the condensation of the carboxylic group of Boc-protected arginine with the corresponding long chain alkylamine [22]. After that, an enzymatic procedure that allowed the preparation of series $\mathbf{2}$ and $\mathbf{3}$ was described [23]. Papain (from Carica Papaya) deposited onto polyamide was found to be the best biocatalyst configuration for the formation of amide (series 2) and ester (series 3) bonds between Cbz-arginine methyl ester and various long chain amines and fatty alcohols. The sodium salts of $\mathrm{N}^{\alpha}$-acyl arginine (Figure 2, series 4) are amphoteric surfactants that contain one positive charge (guanidine group) and one negative charge (carboxylic group) on the polar head. The net charge of these surfactants depends on the 
$\mathrm{pH}$ of the medium. These compounds were prepared by chemical hydrolysis of the corresponding $\mathrm{N}^{\alpha}$-acyl arginine methyl esters [24].

Surfactants of series 5 (Figure 2) have a hydrophobic chain attached to the glycerol backbone through ester bonds and a polar head from the arginine with two positive cationic charges. Structurally, they can be regarded as analogues of the monoglycerides. Their preparation involved a three-step procedure, beginning with the formation of an ester linkage between the carboxylic acid of the protected arginine and the terminal $\mathrm{OH}$ group of the glycerol. The other terminal free hydroxyl group of the intermediate was then acylated with the corresponding long chain acid chloride, and finally, the protected group of the arginine was removed by catalytic hydrogenation [25].

Some of the basic physicochemical properties [critical micellar concentration $(\mathrm{cmc})$, surface tension at the $\mathrm{cmc}\left(\gamma_{\mathrm{cmc}}\right)$ and minimum area per molecule $\left.\left(\mathrm{A}_{\min }\right)\right]$ were obtained from the surface/concentration curves at $25^{\circ} \mathrm{C}$ (Table 1). The cationic single chain arginine-based surfactants presented good aqueous solubility, whereas amphoteric surfactants (series 4) were only sparingly soluble in water, making it impossible to determine the cmc. [24].

The cmc of these surfactants is mainly governed by the alkyl chain length. In all the cationic series, the more methylene groups in the hydrophobic moiety, the lower the $\mathrm{cmc}$, as would be expected from the increasingly hydrophobic character of the molecule [26]. Surfactants from series 5 (arginine monoglycerides) showed slightly lower cmc than those from series 1, 2 and 3 [27]. The presence of the glycerol backbone increases the distance between the ionic group and the $\alpha$-carbon atom of the hydrophobic group, resulting in a lower cmc. The area per molecule of surfactants with two positive charges on the polar head was larger than that of surfactants with only one cationic charge (series 1). The two positively charged groups in series 2 and 3 tended to spread themselves out on the interface due to an increase in electrostatic repulsions [26].

TABLE 1 


\section{Antimicrobial properties of single chain arginine-derived surfactants}

The antimicrobial activity of these derivatives, based on the minimum inhibitory concentration ( $\mathrm{MIC} \mu \mathrm{g} / \mathrm{mL}$ ), is presented in Table 2. In the case of these single chain arginine-based surfactants, the MIC occurred below the corresponding cmc, suggesting that the species interfering with the cellular surface are monomers, not aggregates [26]. As shown in Table 2, these compounds have a wide spectrum of action and exhibited good inhibitory behavior including Gram-negative bacteria. The antimicrobial efficiency of these surfactants was affected by the alkyl chain length, the maximum activity of surfactants of series 1 was obtained for alkyl chain of 12 carbon atoms (Table 2). The methyl ester or ethyl ester group in the analogues LAM and LAE did not affect the antimicrobial activity, both compounds showing a similar range of MIC values.

The antimicrobial activity of cationic surfactants in general depends on the length of the alkyl chain, although the correlation is not clear. Other parameters, such as aqueous solubility, cmc, hydrophobicity and adhesion, also determine the interaction of surfactant molecules with the cellular envelope. Alkyl chains bearing 12 and 14 carbon atoms often show the highest biocidal function. For example, in alkylguanidine-based surfactants, the highest activity also corresponded to the dodecyl derivative. A study of the interaction of these alkylguanidine-based surfactants with bovine serum albumin (BSA) indicated that longer chains enhance the effects on the BSA conformation [28]. Bera et al found in a series of guanidinylated neomycin- and kanamycin-derived surfactants that the number of cationic charges as well as the nature and size of the polycationic head groups affected antibacterial performance, the most active alkyl chains having 11 and 15 carbons. Interestingly, the optimal activity against Grampositive bacteria was achieved by the conjugation of a polyamine head group to saturated $\mathrm{C}_{16}$ or $\mathrm{C}_{20}$ alkyl chains, whereas for the neomycin $\mathrm{B}$-derived polyguanydilated head groups, induction of anti Gram-positive activity was obtained with shorter lipid tails $\left(\mathrm{C}_{12}\right)$ [29].

\section{TABLE 2}


Arg-N-alquyl amide surfactants (series 2) are also very effective agents against Grampositive and Gram-negative bacteria [26]. The tolerance of Gram-negative bacteria to biocides is well known, their outer membrane obstructing biocide entry, due to the intrinsic permeability barrier and the role of lipopolysaccharides, which is not yet understood [30]. Nevertheless, series 1 and 2 analogues exhibited similar levels of activity against both types of bacteria. In series 2 the maximum activity was obtained for ALA with MIC values similar to those obtained for LAM and LAE (series 1). In Series 2 the variation of MIC with the alkyl chain length was less pronounced. An important structural difference between series 1 and 2 was the number of positive charges per molecule. The presence of two cationic charges in series 2 did not affect the performance of the most active compound, enhancing it in the case of $n=10$ and $n=14$. By changing the chemical bond that links the hydrophobic group with the polar head from amide to ester (series 3), the activity decreased drastically. The ester bond might be easily hydrolyzed by bacteria, which would eradicate the antimicrobial activity of the compounds.

The standard monoglycerides (decylglycerol and dodecylglycerol) have no or negligible antimicrobial properties; the introduction of arginine (series 5), which contains a guanidinyl group, confers moderate activity, with no relevant differences between Gram-positive and Gram-negative bacteria [25].

The antimicrobial effect of all these series seems to be linked to the presence of cationic charges, since the sodium salt of $\mathrm{N}^{\alpha}$-acyl arginine hydrochloride (series 4) did not have antimicrobial activity [24]. In homologues of series 4, the positive charge of the guanidyl group is neutralized by the negative charge of the carboxylic group, giving rise to molecules without any net cationic charge.

Although the mechanisms of action of biocides are still far from elucidation, biocide surfactants are known to act predominantly on cellular envelopes. Flow cytometry experiments demonstrated that, after $30 \mathrm{~min}$ of treatment at the corresponding MIC, the LAE (series 1) cause depolarization and disruption of the cellular membrane, which leads to the collapse of the respiratory chain and blockage of the proton motive force (90.7\% of $S$. Typhimurium and $56.3 \%$ of $S$. aureus) [31]. Due to this microbial damage, cell viability is reduced by $98.8 \%$. Ultrastructural changes were also observed by transmission electron microscopy (TEM). This technique detected lesions on the 
cellular envelopes as well as intracellular changes in the appearance of the cytosol in the Gram-negative $S$. Typhimurium. In the Gram-positive $S$. aureus, the microphotographs revealed invaginations of the membrane (mesosomes), abnormal septation and irregular cross-wall formations.

\section{Biological properties of single chain arginine-derived surfactants}

Biological properties of single chain arginine surfactants such as haemolysis, ocular irritation, aquatic toxicity and biodegradability have also been reported. The ability of surfactants to disrupt membrane integrity by a hydrophobic/ionic adsorption phenomenon at the cell membrane /water interface is related with their toxicity. $\mathrm{N}^{\alpha}$-acyl arginine derivatives (series 1) showed moderate haemolytic activity with $\mathrm{HC}_{50}$ values of 38-59 $\mu \mathrm{g} / \mathrm{mL}$ [32]. Their ecotoxicity was evaluated using two aquatic species: Daphnia magna and Photobacterium phosphoreum bacteria. It was found that: (1) the acute toxicity of arginine-derived cationic surfactants was clearly lower than that reported for conventional monoquats, (2) salt water bacterial cells are more sensitive than Daphnia to arginine-derived surfactants, (3) compounds of series $\mathbf{1}$ and $\mathbf{2}$ are more toxic than those of series $\mathbf{3}$ and 5 and (4) acute toxicity grew with increasing hydrophobicity in each series of surfactants, in agreement with cmc values [26,27]. Biodegradation studies indicated that all compounds except AMA can be regarded as readily biodegradable. The rate of biodegradability depends on the alkyl chain length and is accelerated by the incorporation of ester functionality. It can therefore be concluded from available data that hydrophobicity is a negative parameter for the toxicity and biodegradability of arginine-derived surfactants.

\subsubsection{Lysine}

Lysine is an essential basic amino acid that contains one carboxylate and two amino groups. The presence of these three reactive sites allows the synthesis of cationic surfactants with a polar head of variable ionic character by the introduction of hydrophobic groups in the molecule (Figure 3). Amphiphiles with different structures can be designed by hydrophobic modulation, although most of the antimicrobial single chain surfactants from lysine are $\mathrm{N}^{\alpha}$ - or $\mathrm{N}^{\varepsilon}$-acyl lysine derivatives. These $\mathrm{N}$-acyl lysine compounds have the cationic charge on one of the protonated amino groups of lysine, and they present an acid-base equilibrium in aqueous solutions. Given that their cationic character depends on the $\mathrm{pH}$ of the medium, these amphiphiles behave as $\mathrm{pH}$-sensitive 
surfactants. Notably, the pKa of the two lysine amino groups differs considerably, the $\mathrm{pKa}$ of the $\alpha$-amino group is 8.9 while the $\mathrm{pKa}$ of the $\varepsilon$-amino group is 10.5 . At a $\mathrm{pH}$ equal to the $\mathrm{pKa}$, the amino acid will be $50 \%$ protonated, giving an average charge of 0.5 . When the $\mathrm{pH}$ decreases by more than 2 units from the $\mathrm{pH}=\mathrm{pKa}$ value, it can be considered that the amino acid is $100 \%$ protonated and the average charge is 1 . Given this substantial difference in the pKa of the two amino groups of the $\mathrm{N}$-acyl lysine derivatives, the ionic character depends on the position of the cationic charge ( $\alpha$-amino or $\varepsilon$-amino group).

Our group prepared cationic $\mathrm{N}^{\varepsilon}$-acyl lysine methyl ester (Figure 3, series 6) and $\mathrm{N}^{\alpha}$-acyl lysine methyl ester (Figure 3, series 7) to study the influence of the position of the cationic charge on the biological properties of these compounds. The surfactants were synthesized by lysine acylation at the $\varepsilon$ or $\alpha$ position of the protected $\mathrm{N}^{\alpha}$ or $\mathrm{N}^{\varepsilon}$ carbobenzoxi-lysine methyl ester and the protecting group was subsequently removed by catalytic hydrogenation [33]. Cationic surfactant $\mathrm{N}^{\varepsilon} \mathrm{N}^{\varepsilon} \mathrm{N}^{\varepsilon}$-trimethyl- $\mathrm{N}^{\alpha}$-lauroyl lysine derivatives (Figure 3, series 8) were prepared from the corresponding ester of $\mathrm{N}^{\alpha}$ lauroyl lysine by the quaternization of the $\varepsilon$-amino group using methyl iodine. The $\mathrm{cmc}$ of these surfactants is similar, between 2 and $4 \mathrm{mM}$, respectively [34]. Moreover the $\mathrm{N}^{\alpha} \mathrm{N}^{\alpha} \mathrm{N}^{\alpha}$-trimethyl- $\mathrm{N}^{\alpha}$-miristoyl lysine methyl (MKM) $)_{\mathrm{q}}$ ester was also prepared using the same methodology (Figure 3, series 9).

Lysine-based surfactants in which the hydrophobic part is linked to the carboxylic lysine group through an ester or amide bond have also been described. Nakamiya et al. prepared amino acids lauroyl ester (Figure 3, series 10) and lysine lauroyl amides (Figure 3, series 11), which can contain in the molecule 1 or 2 positive charges [35]. Using classical reactions in peptide chemistry, Mondal el al. synthesized a lauroyl amide of lysine (Figure 4, 12), guanidinylated lauroyl amide of lysine (Figure 4, 13) and polyol-modified carbohydrate-templated lauroyl amide of lysine (Figure 4, 14). These authors studied how these structural modifications affected the antimicrobial properties of these compounds [36].

\section{TABLE 3}

The pKa values of the $\mathrm{N}$-acyl lysine methyl ester derivatives indicated that their cationic character depends on the $\mathrm{pH}$ of the medium (Table 3). This behavior is common in 
amino acid-based surfactants, as well as in other cationic surfactants in which the cationic charge is on a protonated amine group [37]. The introduction of hydrophobic groups in the amino acid drastically reduces the apparent $\mathrm{pKa}$, the decrease being more pronounced the longer the hydrophobic group [38]. For the same alkyl chain length, the pKa values of $\mathrm{N}^{\alpha}$-acyl lysine derivatives were higher than those of the $\mathrm{N}^{\varepsilon}$-acyl- lysine methyl ester, whereas the $\mathrm{cmc}$ were in the same order.

\section{Antimicrobial properties of lysine-based surfactants}

MIC values of the $\mathrm{N}^{\alpha}$-lauroyl-Lysine methyl and ethyl ester hydrochloride analogues (series 7) are summarized in Table 4. This family of lysine surfactants exhibited a wide spectrum of antimicrobial activity against Gram-positive and Gram-negative bacteria, with MIC values in the same order as those of arginine analogues [34]. The stereochemistry of these $\mathrm{N}^{\alpha}$-lauroyl-Lysine surfactants did not influence their antimicrobial properties, which did not differ significantly between DL-LLM and LLLM. The fact that these surfactants maintained their activity independently of their optical purity is of great interest, given the high cost of isolating pure diasterioisomers [39]. The ethyl derivative analogue (series 7, LLE) showed higher activity than the methyl analogue (series 7, LLM). No changes were observed when three methyl groups were introduced into the amino group of these molecules (series 8, LLM ${ }_{q}$ and $\mathrm{LLE}_{\mathrm{q}}$ ). The comparable antimicrobial activity of the trimethylated and non-trimethylated derivatives could be ascribed to their similar cationic charge density. The $\mathrm{pKa}$ of the $\mathrm{N}^{\alpha}$ acyl-lysine surfactants was around 9 (Table 3); in the medium used to determine the MIC, all molecules were protonated and the net cationic charge can be considered as 1 per molecule [40]. As the trimethylated analogues have a fixed positive charge independently of the $\mathrm{pH}$, the net positive charge was also 1 .

After the alkyl chain was moved from the $\alpha$-amino to the $\varepsilon$-amino group of lysine, the antimicrobial properties decreased considerably (series 6), and none of the homologues showed activity against Gram-negative bacteria [33,40]. Usually antimicrobial surfactants have less impact on Gram-negative bacteria, since the lipopolysaccharidepacked outer envelopes prevent the entrance of amphiphilic compounds. The MIC values obtained for all these lysine derivatives confirmed that the cationic charge density of surfactants strongly affects their biocide character. Indeed, the LLS surfactant 
(series 7), amphoteric without any charge, was not active against any of the bacteria tested [34]. Taking into account the pKa values of series 6, it can be assumed that the cationic charge density of these surfactants is lower than that of LLM or LLE (series 7). Moreover, it was observed that, by fixing the cationic charge in the $\mathrm{N}^{\varepsilon}$-Miristoyl-lauroyl methyl ester (series 9, $\mathrm{MKM}_{\mathrm{q}}$ ), the activity improved considerably [40]. Then, for amino acid-based cationic surfactants in which the cationic charge lies on a protonated amine group, the antimicrobial activity depends on the $\mathrm{pKa}$ of the latter. Compounds with $\mathrm{pKa}$ values higher than 9 exhibit good activity, while those with a $\mathrm{pKa}$ lower than 7 are less potent, especially against Gram-negative microorganisms.

Nakamika reported the activity of compounds consisting of one amino acid, with one alkyl chain linked to the carboxylic group of the amino acid through an ester bond (series 10). Compounds prepared with basic amino acids (lysine and arginine) containing two positive charges showed good antimicrobial activity against the three microorganisms tested (E. coli, S. aureus, P. aeruginosa). However, the surfactants prepared with neutral amino acids (valine, proline, pheylalanine etc.), bearing a single positive charge on the $\alpha$-amino group of the amino acid, only affected one of the bacteria tested [35]. The pKa of the $\alpha$-amino group of amino acids linked to alkyl chains is about 6-7, which means that solutions prepared with these compounds at $\mathrm{pH}=7$ contain a high percentage of non-protonated molecules and consequently the surfactant antimicrobial activity is low. These authors did not observe any variation in biocide activity after substituting the ester bond by an amide bond (series 11), in contrast with the results obtained by Moran el al. for similar arginine derivatives [26].

The MIC values obtained by Mondal et al. for compound 12 agree with those published previously for similar derivatives with different counterions [36]. This surfactant also showed good activity against Methicillin-resistant $S$. aureus and Methicillin-resistant $S$. epidermidis (MIC values of 4 and $8 \mu \mathrm{g} / \mathrm{mL}$, respectively). The guanidinylation of the two amino groups of lysine in compound 12 (compound 13) enhanced antibacterial performance. However, the substitution of lysine in cationic lipid $\mathbf{1 2}$ by a glucotemplated lysine (compound 14) enhanced the hydrophobicity of the polar group and reduced antibacterial activity.

It is known that biocides have multiple targets. The first interaction of surfactants occurs at the solid/liquid interphase on the envelope of the microbial cell. They then 
interact with the cytoplasmic membrane at different levels, disrupting the cellular membrane and damaging the proton motive force and enzyme transport or enzymeassociated membrane activity. Once the biocide enters the cytoplasm, variable damage might be expected, depending on the compound or the nature of the bacterial cell. Transmission electron microscopy (TEM) revealed that $S$. aureus cells treated with LLM (series 7) at MIC $(63 \mu \mathrm{g} / \mathrm{mL})$ had vesicles in the peripheral region of the cytoplasm, as well as bubbles protruding from the cell mesosomes (Figure 5, a, b) [41]. When an E. coli population was treated with LLM (series 7) at MIC (125 $\mu \mathrm{g} / \mathrm{mL})$ (Fig $5 \mathrm{c}, \mathrm{d})$, it was observed collapse of part of the cytoplasm as well as numerous vesicles in the extracellular space. However, no disruption of the inner membrane was observed.

The main parameters that affected the haemolytic activity of monocatenary lysine surfactants were the same that governed their antimicrobial activity: the alkyl chain length and cationic charge density. Compounds from series 6 showed low pKa values and consequently their cationic charge density at neutral $\mathrm{pH}$ was also low. These surfactants showed little haemolytic activity ( $\mathrm{HC}_{50}$ values > $200 \mu \mathrm{g} / \mathrm{mL}$ ) and the disruption of red blood cells decreased as the alkyl chain lengthened [33]. For the same 12-carbon alkyl chain, the haemolytic activity increased by increasing the charge density; the $\mathrm{HC}_{50}$ of LKM (series 6) was $391 \mu \mathrm{g} / \mathrm{mL}$, while $\mathrm{HC}_{50}$ of LLM (series 7) was $199 \mu \mathrm{g} / \mathrm{mL}[40]$.

\subsubsection{Other amino acids}

Low molecular-weight gelators have generated significant interest in biomedicine. Cationic surfactants based on L-tryptophan (Figure 6, series 15) and L-tyrosine (Figure 6, compounds 16) have proved to be excellent gelators and exhibit remarkable bactericidal properties. Surfactants from series 15 were prepared by coupling Bocprotected L-tryptophan with hexadecylamine using dicyclohexylcarbodiimide (DCC), and the Boc protector group was subsequently removed by trifluoroacetic acid (TFA) [42]. The chloride counterion of these tryptophan-based surfactants was changed to various organic carboxylates in order to investigate counterion-induced variation in antimicrobial activity and cytotoxicity [43].

For $n=15$, the critical concentration at which the surfactant of series 15 and the compound 16 (Figure 6) began to self-assemble ( $\mathrm{cmc}$ ) was 0.13 and 0.08 , respectively. 
These cationic surfactants developed spontaneous vesicles by mixing at room temperature transparent aqueous solutions of these cationic surfactants and anionic surfactants like sodium dodecyl sulphate (SDS). The presence of aromatic groups favored the formation of vesicles [44].

All cationic surfactants from series 15 with $\mathrm{X}=\mathrm{Cl}$ showed potent antibacterial activity against Gram-positive and Gram-negative bacteria. Optimum results were obtained with an alkyl chain length of 10 to 14 carbon atoms, particularly against Gram-negative bacteria with MIC values of $0.5-5.0 \mu \mathrm{g} / \mathrm{mL}$. Compounds with long alkyl chains $(\mathrm{n}=15$ and 17) maintained activity against Gram-positive bacteria, but did not inhibit the growth of Gram-negative bacteria. These amphiphiles showed very low toxicity to mammalian cells: $\mathrm{HC}_{50}$ values were in the range of $100-250 \mu \mathrm{g} / \mathrm{mL}$ for short alkyl chains and 1000 for long alkyl chains, with almost negligible toxicity against HeLa cells. Changing the counterion from chloride to the more hydrophobic organic carboxylates enhanced activity against Gram-positive bacteria and fungi, and improved biocompatibility toward eukaryotic cells. Moreover, supramolecular assemblies of hydrogelator surfactants based on tryptophan (series 15, $\mathbf{n = 1 5}$ ) and tyrosine (compound 16) were used for in situ synthesis of silver nanoparticles to improve their antimicrobial performance [45]. Pure compounds only affected the Gram-positive bacteria, although it was observed that the combination of bactericidal AgNP within self-assemblies of antibacterial surfactant gelators led to the development of soft nanocomposites with activity against both Gram-positive and Gram-negative bacteria.

Antimicrobial cationic surfactants from L-phenylalanine and L-tyrosine (Figure 7, series 17) were reported by Joodan et al., in which the alkyl chain is linked to the carboxylic group of the amino acid through an ester bond [46]. Two different methodologies were used to prepare these ester derivatives. Phenylalanine compounds with short alkyl chains were prepared by mixing the amino acid with the corresponding alcohol with posterior addition of thionyl chloride. Phenylalanine compounds with long alkyl chains were synthesized using p-toluene sulfonic acid as a catalyst. In both series of surfactants, the cmc decreased linearly as the hydrophobic alkyl chain lengthened, ranging from $3.9 \mathrm{mM}$ for the surfactant with $\mathrm{n}=7$ to $0.007 \mathrm{mM}$ for $\mathrm{n}=19$ (Table 5). These cationic surfactants showed good activity toward Gram-positive and low activity against Gram-negative bacteria. Their activity increased with the alkyl chain length, exhibiting a cut-off effect at $\mathrm{C}_{12}$. The interaction of these surfactants with phospholipid 
vesicles showed that both electrostatic and hydrophobic interaction between surfactants and biological membranes affect their antibacterial properties.

\section{TABLE 5}

Sodium $\mathrm{N}$-acyl isoleucines were prepared using a mixture of fatty acids obtained from coconut, palm, jatropha, karanja and high oleic sunflower oil. These amphoteric surfactants showed good surface active and emulsifier properties. Some also presented moderate antimicrobial activity [47].

\subsection{Single chain surfactants with two or more amino acids on the polar head}

Our group prepared a range of single chain surfactants with two amino acids on the polar head. The alkyl chain length and the type of amino acid were varied to explore how these structural parameters affect physicochemical properties and antimicrobial activity (Figure 8) [48].

Amphoteric and cationic $\mathrm{N}^{\alpha}$-Lauroyl arginine dipeptides were prepared from pure amino acids (glycine, phenylalanine, glutamic acid and lysine) on a laboratory scale, following a four-step procedure (Figure 8, series 18): (1) acylation of N-nitro arginine with lauroyl chloride; (2) condensation of the second amino acid by peptide coupling; (3) nitrodeprotection and (4) saponification [49]. $\mathrm{N}^{\varepsilon}$-lauroyl lysine-lysine (Figure 8, 19, LKKM) has also been prepared by our group following a similar chemical protocol [40]. LALM (Figure 8, 18), LAKM (Figure 8, 20) and LKKM (Figure 8, 19) each have two cationic charges. LALM has one on the arginine guanidine group and the other on the lysine $\varepsilon$-amino group. In LAKM the second cationic charge is located on the lysine $\alpha$-amino group. LKKM has both cationic charges situated on the lysine $\alpha$-amino group.

Long-chain $\mathrm{N}^{\alpha}$-acyl-L-arginine diamino acid surfactants were also prepared from acidhydrolyzed collagen $\left(\mathrm{C}_{8} \mathrm{AC}-\mathrm{C}_{16} \mathrm{AC}\right)$ (series 21) using a procedure similar to that for the pure derivatives. Waste leather trimmings previously hydrolyzed with $6 \mathrm{~N} \mathrm{HCl}$ at $120{ }^{\circ} \mathrm{C}$ for 24 hours were the source of collagen amino acids [48].

The cmc of cationic surfactants with two amino acids on the polar head depends on the nature of the amino acids (Table 6). Surfactants with two cationic charges presented 
high cmc values because of their reduced hydrophobicity. As expected, the cmc values of the amphoteric surfactants were lower than those of their cationic homologues. The micellization ability of surfactants prepared with hydrolysed collagen was very pronounced, which was ascribed to synergic effects between the different lipopeptides in the mixture.

\section{TABLE 6}

Table 7 shows the MIC values obtained for $\mathrm{N}$-acyl derivatives with two amino acids on the polar head $[49,40]$. It can be observed that the amino acid sequence modulated the activity. While $\mathrm{N}^{\alpha}$-lauroyl-arginine methyl ester and other homologous cationic surfactants (LAM, series 1) showed good antimicrobial behaviour (Table 2), the corresponding amphoteric N-lauroyl-arginine (LAS, series 4) was not active. However, when a neutral amino acid was incorporated into N-lauroyl-arginine, carboxylic protection was not necessary. In fact, the cationic LAGOM and LAPOM (series 18) showed similar antimicrobial activity to their amphoteric homologues LAGOH and LAPOH (series 18) (Table 7). The second non polar amino acid avoids electrostatic interaction between the guanidine and the carboxylic group, leaving the cationic charge of the guanidine free. Activity was drastically reduced by the incorporation of glutamic acid (LAGuOM and $\mathrm{LAGuOH}$, series 18); in this case, the guanidine group can react with the $\beta$-carboxylic group of the glutamic acid, neutralizing the cationic charge of the molecule. The addition of lysine as a second amino acid also reduced antimicrobial activity (LALM series 18, LAKM 20). The presence of two cationic charges on the polar head increases the hydrophilic character of the molecule and consequently reduces surface tension and biocide activity. The combination of two lysine amino acids (LKKM) was less effective than combing an arginine with a basic or neutral amino acid, particularly in the compound with two cationic charges on the two lysine $\alpha$-amino groups The best activity was obtained with the arginine-phenylalanine sequence (LAPOM, LAPOH, series 18), perhaps due to the combination of the aromatic ring with the charged guanidine group. On the other hand, the $\mathrm{N}^{\alpha}$-acyl derivatives in which the second amino acid came from hydrolysed collagen showed only moderate antimicrobial activity with MIC values between 64 and $256 \mu \mathrm{g} / \mathrm{mL}$.

\section{TABLE 7}


These results indicate that the amino acid sequence, the physicochemical properties of the molecule and the cationic charge density are parameters that significantly affect the antimicrobial properties of these types of surfactants.

Potent antimicrobial and antifungal agents consisting of one alkyl chain of 16 carbon atoms and two, three and four amino acids have been reported (Figure 9, series 22) [50]. Shai et al. showed that each of these palmitoyl-lipopeptides assemble in solution into nanostructures with different morphologies, which could partially explain the changes in their antimicrobial activity. The introduction of one alkyl chain into inactive cationic tetra- or tripeptides gave rise to powerful antimicrobial and antifungal compounds. Cell specificity was determined by the sequence of amino acids on the polar head and the length of the aliphatic moiety. For alkyl chains bearing 16 carbon atoms, the lysinelysine-lysine sequence showed the highest antimicrobial activity towards all tested bacteria with MIC values lower than $15 \mu \mathrm{M}$. The lysine-alanine-lysine sequence was completely inactive against all tested cells, lysine-leucine-lysine was active only towards Gram-positive bacteria and lysine-glycine-lysine showed activity against all tested microorganisms. The lysine-glycine-glycine-lysine sequence combined with a palmitoyl alkyl chain was the most active tetrapeptide derivative. The biological activity remained similar when an L-amino acid was substituted by its D-enantiomer.

Interestingly, it was observed that the mode of action of these compounds involves membrane permeation and disintegration. In contrast with most known AMPs or natural lipopeptides, which are active either only on bacteria or on fungi, several compounds of this family were very active against both. Further, most of these derivatives were practically not haemolytic at their MICs or at higher concentrations [51]. Serrano et al. later showed that replacing the $\alpha$-amino acids by $\beta$-aminoacids did not affect the activity of the corresponding lipopeptide [52].

Using solid phase synthesis, Lohan et al. designed and prepared short lipopeptide molecules consisting of ornithine units conjugated with fatty acids (series 23, Figure 10) [53]. Compounds with ornithine residues ranging from 2 to 5 units and alkyl chain lengths from $\mathrm{C}_{12}$ to $\mathrm{C}_{18}$ showed very good antimicrobial activity against fungi as well as both Gram-positive and Gram-negative bacteria, including clinically relevant methicillin-resistant S. aureus and S. epidermis (MRSA and MRSE), which are resistant to most antibiotics. Among the synthesized compounds, the most active was a 
lipopeptide composed of three ornithines bearing one $\mathrm{C}_{14}$ alkyl chain. This compound showed potent activity with MIC values of $1.5 \mu \mathrm{g} / \mathrm{mL}$ for E. coli, P. aeruginosa, and $S$. aureus, $6.25 \mu \mathrm{g} / \mathrm{mL}$ for B. subtilis, $6.24 \mu \mathrm{g} / \mathrm{mL}$ for MRSE and $12.5 \mu \mathrm{g} / \mathrm{mL}$ for MRSA. All these ornithine derivatives presented low haemolytic activity, with $\mathrm{HC}_{50}$ values higher than $250 \mu \mathrm{g} / \mathrm{mL}$. The results indicate that these compounds are able to kill microbes without any lytic activity towards mammalian erythrocytes.

Antimicrobial dipeptide-based amphiphiles with varying head group structures were also obtained by Das et al., featuring different combinations of three amino acids: phenylalanine, proline and tryptophan (Figure 11, 24, 25, 26, 27, 28, 29) [54]. In a multistep synthesis, Boc-protected amino acids were coupled with the methyl ester of the corresponding L-amino acids using dicyclohexylcarbodiimide (DCC) and a catalytic amount of dimethylaminopyridine (DMAP) in the presence of N-hydroxybenzotriazole (HOBT). After purification, this intermediate was subjected to saponification by the addition of $\mathrm{Na}(\mathrm{OH})$. The free carboxylic group was then coupled with ntetradecylamine using DCC and a catalytic amount of DMAP in the presence of HOBT. Finally, the BOC-protected group was removed with trifluoroacetic acid.

These amphiphiles presented notable hydrogelation efficiency at a wide range of minimum gelation concentrations ( $\mathrm{MGC}=1.2-22 \%$ ) and marked growth inhibition of both Gram-positive (MIC values between 1-50 $\mu \mathrm{g} / \mathrm{mL}$ ) and Gram-negative bacteria (MIC values between 5-150 $\mu \mathrm{g} / \mathrm{mL}$ ) as well as fungus (MIC values between 1-50 $\mu \mathrm{g} / \mathrm{mL}$ ). The most active compounds were those with Phe-Pro (24) and Trp-Pro (26) in the head group. The effect of these amphiphiles on the morphology of bacterial cells was studied using scanning electron microscopy. The SEM images showed collapse in the membrane integrity of lysed E.coli and S. aureus while remaining intact in untreated bacteria. Interestingly, the cytotoxicity of all the dipeptide-based amphiphiles against human cancer-derived HepG2 cells and human cervical cancer-derived SiHa and HeLa cells was very low. In fact, a maximum of only $36 \%$ cytotoxicity against HeLa cells was observed in compound $\mathbf{2 6}$ at a concentration of $200 \mu \mathrm{g} / \mathrm{mL}$.

Linoleic acid-dipeptide-spermidine conjugates have also been proposed as antimicrobial agents $(\mathbf{3 0}, \mathbf{3 1}, \mathbf{3 2})$. These amphiphiles contained linoleic or stearic acid linked to a polyamine polar head combining two amino acids (tryptophan and ornithine) conjugated with spermidine [55]. The hydrophobic tryptophan amino acid was chosen 
because of its membrane-anchoring property [56] and ornithine was used to impart protease stability to the amphiphiles due to its non-ribosomal origin. The sequences were synthesized using a combined solid phase and solution phase strategy involving several steps. Briefly, the dipeptides were prepared on a solid support using Fmoc chemistry. Then the condensation between the fatty acid and the dipeptide was achieved using HOBT and N,N'-diisopropylcarbodiimide (DIPCDI). Finally, the $\mathrm{N}^{1}, \mathrm{~N}^{4}$ bis(boc)spermidine was linked to the carboxylic group of the dipeptide, also using HOBT and DIPCID in a solution of dry tetrahydrofuran.

Intermediates containing only the dipeptide with spermidine did not show antimicrobial activity, while those without the spermidine residue (peptide+fatty acid) inhibited bacterial growth only to a low extent. Sequences containing long alkyl chains (linoleic or stearic acid) and spermidine exhibited potent activity against susceptible and drug resistant Gram-positive and Gram-negative bacterial strains as well as rapid bactericidal kinetics. Against E. coli and P. aeruginosa, MIC values of these amphiphiles were in the range of 3.5-28.4 $\mu \mathrm{g} / \mathrm{mL}$ and 7.1-14.2 $\mu \mathrm{g} / \mathrm{mL}$, respectively. Against the four Grampositive strains tested, the MIC values were below $15 \mu \mathrm{g} / \mathrm{mL}$. These data revealed that to obtain efficient antimicrobial compounds, a hydrophobicity window combined with a determined number of cationic charges is crucial. In general, the mode of action of these amphiphiles involved disruption of the bacterial membrane. However, they were also able to alter the electrophoretic mobility of DNA, which may also have enhanced the activity of these sequences. The dipeptide sequence played a predominant role in the mode of action. At MIC, compound $\mathbf{3 0}$ showed low membrane leakage and depolarization. It reduced DNA binding ability, suggesting that membrane destabilization is a less probable mode of action and that other vital functions in bacterial cells could be affected. However, at a higher concentration, a membrane disruptive mode of action was evident. Compound $\mathbf{3 1}$ clearly induced membrane perturbance, while compound $\mathbf{3 2}$ showed rapid bactericidal kinetics, causing moderate levels of leakage. This behaviour was ascribed to the formation of transient pores or pores not large enough to cause much leakage. Also remarkable was the low haemolytic activity of these compounds, most of them being non-haemolytic up to $62 \mu \mathrm{g} / \mathrm{mL}$. Additionally, results of the MTT assay in HaCaT cells showed more than $80 \%$ cell survival at $62 \mu \mathrm{g} / \mathrm{mL}$. 
As this summary indicates, the combination of two or three amino acids on the surfactant polar heads can create very effective antimicrobial agents. Their potency increases when the peptide sequence contains an aromatic amino acid such as tryptophan, combined with another with a cationic charge. Arg and Trp are found in unusually high proportions in numerous antimicrobial peptides. Apart from their positive charge, the specific properties that these amino acids bring to antimicrobial peptides are still unclear. The aromatic indole side chain has an extensive $\pi$-electron system that gives rise to a significant quadruple moment, which can be considered as two dipole moments extending perpendicularly out of either side of the ring plane. The $\pi$-electron system of Tryptophan or other amino acids with aromatic groups results in negatively charged clouds that can participate in cation- $\pi$ interactions between this negatively charged electron cloud and positively charged side chains of arginine [57]. These cationic- $\pi$ interactions make the entry of arginine into the hydrophobic environment inside a lipid bilayer energetically more favourable. Moreover, when the Arginine residue is involved in these cationic- $\pi$ interactions, hydrogen bonds can still be formed. The cationic charge of amino acids enhances the attraction of peptides or antimicrobial agents to the membranes, and hydrogen bonding promotes interaction with negatively charged surfaces such as LPS or phosphatidylglycerol phospholipid head groups. On the other hand, it has been reported that Tryptophan residues have a preference for the interfacial region of lipid bilayers [58] the large indole side chain disrupting the cohesive hydrophobic interactions of the lipid acyl chains when it buries deeper into the hydrocarbon core of a lipid bilayer. Because of that, it has been proposed that the complex electrostatic nature of the interfacial region of the lipid bilayers is ideal to accommodate Tryptophan residues. Overall, the combination of the cationic charge of amino acids with the special properties of Tryptophan or other aromatic amino acids seems to improve the antimicrobial properties of peptides [59].

\subsection{Double chain surfactants}

\subsubsection{Glycerolipidic structures}

\section{Arginine diacyl-glycerolipid conjugates}


Arginine glycerolipid conjugates constitute a novel class of lipoamino acids, which can be considered analogues of partial glycerides and phospholipids (Figure 12, series 34). They consist of two aliphatic chains and one amino acid on the polar head, linked by a glycerol moiety (Fig12, series 35 and 36).

Structurally, these compounds have a central skeleton of glycerol that links the hydrophobic part, formed by two fatty chains of variable length, to the hydrophilic part, formed by arginine or acetyl-arginine linked to the glycerol by its terminal hydroxyl through an ester bond $[60,61]$. This family of compounds combines in one molecule the physicochemical properties of glycero derivatives and polar arginine-based surfactants, conferring certain advantages over conventional phospholipids: a) the introduction of arginine in the polar head increases their solubility in aqueous solution; b) the cationic characteristics associated with arginine endow the amphiphilic molecule with antimicrobial activity and c) the fatty chains allow the molecule to aggregate spontaneously in water.

The synthesis of the XXR compounds (Figure 12, series 35) was successfully achieved following a three-step chemical procedure [60], starting from commercially available $\mathrm{N}$ Cbz-L-arginine-rac-glycerol.HCl. The first step was to bind the glycerol and the protected arginine via chemical esterification of the arginine $\alpha$-carboxyl group with the primary hydroxyl function of glycerol. The second step was the acylation of the two remaining free hydroxyl groups with the corresponding long-chain acid chlorides. The third and last step was the catalytic hydrogenation of the arginine protecting group using Pd over charcoal. The following compounds were obtained: 88R, 1010R, 1212R and 1414R (series 35).

The compounds XXRAc (Figure 12, series 36) were synthesized using chemical and enzymatic methodologies [61b]. Both methods have in common the first stage of the synthesis, which is the enzymatic preparation of the arginine glyceryl ester derivative. This reaction consisted of the selective protease-catalysed esterification of one of the primary hydroxyl groups of the glycerol with the arginine carboxylate group. The second step involved the preparation of XXRAc compounds by chemical or enzymatic acylation of the two remaining free hydroxyl groups with the corresponding long-chain acid chloride

The surfactant phase behaviour is largely dependent on the packing possibilities of the molecules [62]. As XXR and XXRAc bear two hydrophobic chains, they have a larger 
cross section than single chain surfactants and, based on simple packing restrictions, the preferred packing will obviously be in the form of flat structures. This has a concomitant effect on a small critical micellar concentration, the formation of vesicles at low concentration in water and the formation of lamellar liquid crystals at a high concentration. When the cmc of the XXR (series 35) compounds was systematically studied, a large discrepancy between methods was apparent [63]. Conductivity and fluorescence gave values of $5 \mathrm{mM}$ and $7 \mathrm{mM}$ for $88 \mathrm{R}$, while a value of only $0.07 \mathrm{mM}$ was obtained from surface tension (Table 8). This disparity was attributed to the formation of premicellar aggregates. Further studies established that the low value obtained by surface tension was due to the formation of vesicles at very low concentrations [64]. The cmc values of the XXR and XXRAc compounds differed from short-chain lecithins. Short chain phospholipids aggregate in water, forming micelles at concentrations of about $16.5 \mathrm{mM}$ for $\mathrm{diC}_{6}$-lecithin and $0.24 \mathrm{mM}$ for $\mathrm{diC}_{8}$-lecithin [65]. The cmc values of arginine diacyl-glycerolipid conjugates with the same fatty chain length (Table 8) are one order of magnitude higher, which can be attributed to a higher solubility.

\section{TABLE 8}

Spread monolayers of two compounds of the XXRAc family, 1212RAc and 1414RAc (series 36), were studied alone [66] and in mixtures with 1,2-dimiristoyl-phosphatidyl choline (DMPC) and 1,2-palmitoyl-phosphatidyl choline (DPPC) [67]. Interactions between components in mixed monolayers were studied from the point of view of their miscibility. All mixtures presented partial miscibility between the two components, and the monolayer was thermodynamically favoured, with the exception of 1212RAc/DMPC.

\subsubsection{Double chain surfactants from lysine}

Lysine-bisglycidol conjugates are lysine-based cationic amphiphilic molecules that combine several hydroxyl functions and aliphatic chains with 12 or 14 carbon atoms (Figure 13, series 37, 38, 39) [68].

These molecules show two main features: a lysine methyl ester residue as the polar group, which confers a cationic character to the molecule and is linked to a bisglycidol chain, and a residue of bis(2,3-dihydroxypropyl), which can carry from one to four aliphatic chains as part of the hydrophobic moiety. In addition, the lysine group is 
bonded to the polyol skeleton through an $\mathrm{N}$-alkyl amine, which increases chemical stability compared to the diacyl-glycerol arginine derivatives. One important drawback of the classical cationic surfactants is their low biodegradability in aerobic conditions due to the N-C linkage between the alkyl chain and the cationic group. In lysinebisglycidol, the presence of an ester-type linkage between the hydrophilic moiety and the hydrophobic backbone ensures high biodegradability.

The synthesis of these compounds involved four steps: (1) esterification of the protected lysine, (2) aminoxylation of the esterified lysine with an excess of glycidol, (3) esterification of the hydroxyl functions with fatty acyl chlorides and (4) deprotection of lysine by catalytic hydrogenation to obtain the final compounds. The key step of this synthetic strategy is the reaction between the protected lysine and glycidol, which is easy to perform and guarantees good yields.

The $\mathrm{cmc}$ and critical aggregation concentration were determined by surface tension, conductivity, and chloride ion activity. Based on conductivity and chloride ion activity, the cmc of the double-chain LGGdi12 and LGGdi14 (series 38) were 0.5 and $0.4 \mathrm{M}$, respectively. The most striking feature of the cmc values is the great disparity between those obtained by surface tension compared with the other two techniques. Such discrepancy between interface and bulk techniques in the determination of $\mathrm{cmc} / \mathrm{cac}$ is reported in the literature [69].

\section{TABLE 9}

The arginine diacyl-glycerolipid conjugates as well as the lysine bisglycidol derivatives showed antimicrobial activity against a wide range of microorganisms, including Gramnegative bacteria (Table 9) [60,68]. Among the XXR (series 35) surfactants, the maximum activity corresponded to the compound with 8 carbon atoms in the alkyl chains, the activity decreasing with longer alkyl chains. The most active dyglyceride derivative (88R, series 35) performed similarly to LAM or LAE (series 1), the most active $\mathrm{N}^{\alpha}$-acyl-arginine surfactants. It should be taken into account that $88 \mathrm{R}$ (series 35) and LAM (series 1) had a similar cme and the cationic charge in both surfactants lay in a guanidine group. Thus, two of the parameters that control antimicrobial behaviour, hydrophobic-hydrophilic balance and charge density, were similar in the two compounds. The XXRAc (series 36) derivatives showed slightly more activity than their corresponding homologues, 1212R and 1414R (series 35) [61]. Antimicrobial 
properties can be enhanced by increasing the number of cationic charges on the polar head, so the XXR surfactants could be expected to be more active. However, the 1212R has the second cationic charge on the $\alpha$-amino group of arginine and this group is not protonated at $\mathrm{pH}=7.2$ (Muller Hinton medium). Moreover, the solubility of XXRAc is slightly higher than that of the corresponding XXR homologue; it seems that the hydrophilic character of XXRAc was enhanced by the incorporation of the amide bond, which can easily form hydrogen bonds. The lysine derivative LGGdi12 (series 38) also showed greater activity than 1212R (series 35), its two free hydroxyl groups providing solubility. The $\mathrm{HC}_{50}$ values of the XXR (series 35) derivatives were higher than those of typical cationic surfactants based on quaternary ammonium groups. In this surfactant family, the haemolytic activity decreased when the hydrophobicity of the molecules increased. In fact, $88 \mathrm{R}$ exhibited an $\mathrm{HC}_{50}$ value of $24 \mu \mathrm{g} / \mathrm{mL}$, while the $\mathrm{HC}_{50}$ of $1414 \mathrm{R}$ was $64.3 \mu \mathrm{g} / \mathrm{mL}[60]$.

Double chain cationic lysine-based surfactants were also synthesized via solid phase peptide synthesis and terminal acylation of their $\alpha$ and $\varepsilon$ positions with saturated fatty acids [70]. Four lipopeptides of $\mathrm{N}^{\alpha}$-acyl- $\mathrm{N}^{\varepsilon}$-acyl lysine-type were prepared (Figure 14, series 40) [71].

\section{TABLE 10}

The $\mathrm{cmc}$ and surface tension values at $\mathrm{cmc}$ are summarized in Table 10. As expected, the cmc strongly depended on the length of the hydrophobic chains attached to the $\alpha$ and $\varepsilon$ amino groups. High surface tension values at $\mathrm{cmc}\left(\gamma_{\mathrm{cmc}}\right)$ were observed for these surfactants, and they increased slightly when the alkyl chain was lengthened.

For this surfactant family, the best antimicrobial activity was found in compounds with alkyl chains of 10 and 12 carbon atoms. $\left(\mathrm{C}_{10}\right)_{2}-\mathrm{KKKK}-\mathrm{NH}_{2}$ and $\left(\mathrm{C}_{12}\right)_{2}-\mathrm{KKKK}-\mathrm{NH}_{2}$ showed high biocide activity against Gram-positive and Gram-negative bacteria with MIC values in the range of 2-64 mg/L. Optimum activity was obtained in derivatives with alkyl chains of 10-12 carbon atoms, in contrast with 8-10 in double chain argininebased surfactants. As these compounds contain a big polar head with four basic amino acids, longer alkyl chains are required to obtain an appropriate hydrophobic-hydrophilic balance. The antifungal activity of these compounds was much weaker, with MIC values in the range of $128-256 \mathrm{mg} / \mathrm{L}$. It was also observed that the antifungal activity was not influenced by the alkyl chain length.. All these compounds, at concentrations of 
$2 \mathrm{mg} / \mathrm{L}$, caused haemolysis $<3 \%$. Above this concentration, the increase in haemolysis depended on the alkyl chain length, the most toxic being $\left(\mathrm{C}_{12}\right)_{2}-\mathrm{KKKK}-\mathrm{NH}_{2}$.

Ahn et al. [72] prepared double chain surfactants in which the polar head consisted of one histidine with one or two arginines, and the hydrophobic part contained two alkyl chains linked to the imidazole group (series 41a, Figure 15). These surfactants possessed one positive charge on the imidazole group and two guanidine groups that can be protonated. Single chain derivatives with only one alkyl chain were also synthesized (series 41b, Figure 15).

The double chain homologues with $n=5$ and $n=8$ displayed potent antimicrobial activity against Gram-negative and Gram-positive bacteria (average MIC range of 3.7-24.0 $\mathrm{mg} / \mathrm{L})$. However, the compound with $\mathrm{C}_{14}$ pendant alkyl chains completely lost these antimicrobial properties. The monoalkylated compound showed similar high activity towards Gram-positive bacteria, but it decreased 2-4 fold against all Gram-negative strains. In addition, these compounds retained their activity against methicillin-resistant strains. By microscopy, it was observed that bacteria treated with these surfactants, at a concentration of 3 times the MIC, showed clear rupturing of cells, with release of internal materials. Interestingly, all these derivatives displayed low haemolytic power, with an $\mathrm{HC}_{50}$ higher than $100 \mathrm{mg} / \mathrm{L}$.

\subsubsection{GEMINI SURFACTANTS}

Dimeric or gemini surfactants are a class of surface active agents composed of two single surfactants chemically linked at or near the head groups by a rigid or flexible spacer chain. Due to the greater amount of hydrocarbon per molecule, the cmc of gemini are typically one order of magnitude lower than of the corresponding monomeric surfactant. They are ten to a hundred times more efficient at reducing the surface tension of water and the interfacial tension than conventional surfactants. Consequently, the application of only small amounts of gemini surfactants can produce great effects.

\section{Cationic gemini surfactants from cystine}

The amino acid cystine consists of two cysteine residues joined by a disulphide linkage and offers a potential material for the synthesis of gemini surfactants. One cationic gemini surfactants from cystine were prepared by Pinazo et al. [73]. This compound had 
two saturated hydrocarbon chains and a complex polar group consisting of two quaternary ammonium salts linked through an alkene spacer chain containing amide and disulfide bonds (compound 42, Figure16).

This surfactant were prepared by condensation of commercial N-lauryl N,N-dimethyl amino betaine with a cystine dimethyl ester using the mixed anhydride method. Cystine was the source of the disulfide function. The cystine-based gemini surfactant showed very low $\mathrm{cmc}, 21 \times 10^{-6} \mathrm{M}$, and moderate to good adsorption efficacy with surface tension at the cmc of $35 \mathrm{mNm}^{-1}$. Also, the estimated area per molecule for dialkyl surfactants was reasonable at $1 \mathrm{~nm}^{2}$. Further studies with products of somewhat lower purity (alleged presence of partial monoalkyl derivatives) produced significantly higher cmc values $\left(65 \times 10^{-6} \mathrm{M}\right)[74]$. The pulsating bubble technique showed that the dynamics of adsorption of these gemini surfactants is slower than the diffusion.

\section{Cationic gemini surfactants from arginine}

Cationic gemini surfactants from arginine, bis(Args) were reported by Perez et al. [75]. The general formula for these compounds is shown in Figure 17, series $\mathbf{4 3}$. They consist of double chain amphiphiles with two hydrophilic chiral head groups from the natural amino acid L-Arg and a polymethylene spacer chain of variable length. The fatty chain is connected through an amide bond to the arginine $\mathrm{N}^{\alpha}$ amino group.

The initial synthetic approach involved chemical protecting groups, deprotection reactions and chemical catalysis. This efficient method enabled a large number of homologues to be easily prepared. The second approach involved chemo-enzymatic strategies [76], in which one amino group of the diaminoalkane spacer underwent quantitative acylation by the carboxylic ethyl ester of the $\mathrm{N}^{\alpha}$-acyl-arginine, followed by a papain-catalyzed reaction between $\mathrm{N}^{\alpha}$-acyl-arginine and the unreacted amino group of the diaminoalkane spacer. Compounds with different alkyl chain lengths, as well as different spacers, were prepared.

Table 11 shows the $\mathrm{cmc}$ and surface tension at the $\mathrm{cmc}$ for gemini surfactants and their corresponding single chain counterpart LAM (series 1). The most striking feature is the very low values of $\mathrm{cmc}$, in the range of a few micromoles per liter, and also the 
considerable difference (three orders of magnitude) compared with the single chain compound [77].

\section{TABLE 11}

\section{Cationic gemini surfactants from lysine}

Four gemini surfactants from lysine (series 44, Figure 18) were prepared, varying the spacer chain and the number and type of cationic charges: two positive charges on the $\boldsymbol{\varepsilon}$-amino groups of the lysine and a methylene-based spacer chain $\left(\mathrm{C}_{6}(\mathrm{LL})_{2}\right)$; two positive charges on the $\alpha$-amino groups of lysine and a methylene-based spacer chain $\left(\mathrm{C}_{6}(\mathrm{LK})_{2}\right)$; two positive charges on the two trimethylated $\alpha$-amino groups of the quaternised lysine and a methylene-based spacer chain $\left(\mathrm{C}_{6}(\mathrm{LK})_{2 \mathrm{Q}}\right)$; and finally, a spermidine-based spacer and two positive charges on the $\alpha$-amino groups of lysine as well as a third positive charge on the spacer chain $\left(\mathrm{C}_{7} \mathrm{NH}(\mathrm{LK})_{2}\right)$ [78].

The surfactants were obtained on a multigram scale with $99 \%$ purity by chemical condensation of the single long-chain N-lauroyl-L-lisine, previously protected, to the corresponding spacer in the presence of an activating agent. A final deprotection reaction was carried out to obtain the desired cationic gemini compounds. As expected, their cmc values were roughly two orders of magnitude lower than the monocatenary homologue. CMC values of $\alpha-$ and $\varepsilon$-linked lysine differed only slightly, at 740 and 500 micromolar, respectively, despite the considerable structural changes involved.

Asymmetric cationic gemini surfactant analogues from lysine, with two quaternary ammonium groups linked to the fluorinated or hydrocarbon alkyl chains through amide bonds and a lysine spacer (Series 45, Figure 19), were prepared by Tan et al. [79].

\section{Antimicrobial properties of gemini surfactants}

Overall, the antimicrobial activity of the gemini surfactants was higher than of their monocatenary counterparts. This was due to several structural and functional features, since the mechanism of action was based on the surface-active properties of the compound.

The antimicrobial behavior of compound $\mathbf{4 2}$ was evaluated against a wide range of microorganisms, including Gram-positive and Gram-negative bacteria. Excellent activity was displayed against all the microorganisms with MIC values from 0.125 to 16 $\mu \mathrm{g} / \mathrm{mL}[80]$. 
Gemini surfactants from lysine and arginine also exhibited antimicrobial activity against a broad spectrum of Gram-positive and Gram-negative bacteria. Several features affected the antimicrobial activity of amino acid gemini surfactants [81, 40]: $i$ ) the length of the spacer alkyl chain (Table 12), ii) the length of the alkyl chain (Table 13) and iii) the type of amino group where the cationic charge is located (Table 14).

TABLE $12,13,14$

Keeping the alkyl chain constant $(x=8)$, the antimicrobial activity decreased with long spacer chains $(n=9, n=10)$, the most favorable being $n=3$ (Table 12). This behavior could be ascribed to aggregate size, gemini with short spacers tend to form spherical micelles while those with large spacers form viscous solutions that contain big three like micelles [82]. The second main feature affecting the antimicrobial activity is the alkyl chain length. The best performing gemini surfactant had alkyl chains of ten carbon atoms $\left(\mathrm{C}_{3}(\mathrm{CA})_{2}\right.$, series 43 , Table 13), while those with 8 carbon atoms $\left(\mathrm{C}_{3}(\mathrm{OA})_{2}\right.$, series 43) showed negligible activity, probably due to high hydrophilicity. Devinsky et al. also found that the antimicrobial performance of bisquat-type gemini surfactants is optimum in the range of 10 to 12 carbon atoms [83]. In general, arginine-based gemini surfactants are more antimicrobial than monomeric compounds. For example, the most active one, C3(CA)2 (series 43), performed better than LAM (Table 2), the most active monocatenary surfactant.

The net cationic charge of the molecules is the third structural feature that significantly affects activity against bacteria (Table 14), which increases with the pKa value [40]. Keeping the alkyl chain (12C) and the spacer (6C) the best performance was obtained with $\mathrm{C}_{6}(\mathrm{LK})_{2 \mathrm{Q}}$ (series 44) (fixed positive charges) and $\mathrm{C}_{6}(\mathrm{LA})_{2}$ (series 43) (cationic charges situated on the guanidine group, $\mathrm{pKa}>10)$. The least active surfactant, $\mathrm{C}_{6}(\mathrm{LK})_{2}$ (series 44) had the positive charge located on the $\alpha$-protonated amine group of lysine (pKa about 6). These means that the average charge of $\mathrm{C}_{6}(\mathrm{LK})_{2}$ at the $\mathrm{pH}$ of the medium used to determine the MIC values could be lower than 2 charges per molecule. The MIC values obtained for these compounds at different $\mathrm{pH}$ values confirmed that the net positive charge affected the antimicrobial activity. In fact, it was observed that the activity of compounds with pKa values lower than 7 increases as the $\mathrm{pH}$ decreases [40]. Rosin et al. prepared cationic gemini surfactants with four cationic charges structurally 
analogous to $\mathrm{C}_{6}(\mathrm{LL})_{2}$. The spacer chain consisted of spermine and consequently contained two positively charged amino groups, and the alkyl chains were substituted by cholyl groups [84]. The results indicate that this surfactant was more active than $\mathrm{C}_{6}(\mathrm{LA})_{2}$.

To assess the effect of $\mathrm{C}_{3}(\mathrm{CA})_{2}$ (series 43 ) on bacterial populations, flow cytometry analysis were performed using dual staining with SYTO-13, a fluorochrome that penetrates the cell binding to DNA, and propidium iodure (PI), a stain not taken up by intact cells, but which penetrates the cell when the membrane is permeabilized [85]. As shown in Fig. 20, in both cases the control population was stained with SYTO-13; in the case of the Gram-positive $S$. aureus, after treatment with $\mathrm{C}_{3}(\mathrm{CA})_{2}$ at $2 / 3 \mathrm{MIC}$, still most of the population $(95 \%)$ remained intact, $2 \%$ was double-stained, suggesting partial damage, and only 3\% appeared as dead cells (stained with PI). E. coli. displayed a different reaction: after treatment at sub-MIC (2/3MIC), most of the population was stained with PI, indicating the cells had been killed by membrane permeabilization.

Electron micrographs supported these results. In $S$. aureus, $\mathrm{C}_{3}(\mathrm{CA})_{2}$ induced the formation of mesomes and cytoplasmic clear zones, but the loss of membrane integrity was lower than in E. coli (Figure 21).

Although MIC values for the lysine-based gemini surfactants (Table 14) were lower than for those with arginine (Table 12,13), they also induced critical damage in bacteria. Electron micrographs of bacteria treated with $\mathrm{C}_{6}(\mathrm{LL})_{2}$ (series 44) confirmed that the gemini mode of action involved a drastic damage to the gram-positive $S$. aureus and gram-negative E. coli (Fig. 21 b). A clear disruption of the cellular membrane and incipient solubilization of the cytoplasm material (white areas) was observed. Cell fragments with a complete collapse of the membrane also appeared in the background of the micrograph [41].

The antimicrobial and antifungal properties of asymmetric cationic gemini surfactants from lysine (series 45) were studied using bacteria, both gram-positive ( $S$. aureus) and gram-negative (E. coli), as well as yeast (C. albicans) and mould (Aspergillus niger). The MIC values $(2-62.5 \mu \mathrm{M})$ were in all cases lower than those of DTAB. The homologue with alkyl chains of ten carbon atoms was again the most active compound and the introduction of fluorinated chains enhanced activity, above all against $C$. albicans [79]. 
The results reported indicated that, in general, cationic gemini surfactants from amino acids show greater antimicrobial activity than their monocatenary homologues, possibly due to a combination of factors: i) low cmc values, ii) good solubility and the presence of two positive charges and iii) two alkyl chains per molecule. Indeed, the introduction of additional positive charges on the spacer chain increased their action. The alkyl chain length affected the antimicrobial activity in the same way as in monocatenary surfactants. In the case of gemini surfactants, optimum activity was obtained with alkyl chains of 10 carbon atoms, while in single chain surfactants, those of 12-14 carbon atoms gave the lowest MIC values.

Regarding haemolytic activity, antimicrobial gemini surfactants from lysine and arginine have generally shown a higher capacity to disrupt erythrocyte membranes than their single chain homologues [40,32]. For example, the $\mathrm{HC}_{50}$ of $\mathrm{C}_{3}(\mathrm{CA})_{2}$ and $\mathrm{C}_{3}(\mathrm{LA})_{2}$ (series 43) was 48.1 and $12.5 \mathrm{mg} / \mathrm{L}$, while their single chain homologues, CAM and LAM (series 1), exhibited $\mathrm{HC}_{50}$ values of 58.8 and 38.5, respectively. It was also observed that the haemolytic activity was enhanced by lengthening the alkyl chain $\left(\mathrm{HC}_{50}\right.$ of $\mathrm{C}_{3}(\mathrm{OA})_{2}>1000 \mathrm{mg} / \mathrm{L}$ and $\mathrm{HC}_{50}$ of $\left.\mathrm{C}_{3}(\mathrm{LA})_{2} 12.5 \mathrm{mg} / \mathrm{L}\right)$ and for the same alkyl chain the haemolysis increased by increasing the spacer length or the cationic charge density of the molecule [40]. However, the size of aggregates in the solution also affected haemolysis. The less active $\mathrm{C}_{12}(\mathrm{LA})_{2}$ and $\mathrm{C}_{9}(\mathrm{LA})_{2}$ had two alkyl chains in very close proximity, resulting in the formation of large aggregates in aqueous solution, which hampered interaction with biological membranes [86].

The haemolytic power of lysine- and arginine-derived gemini surfactants differs considerably from those based on quaternary ammonium (bis(Quats) [87]. While the amino acid-based gemini surfactants showed hemolytic activity at 9-400 mg/L,[32,40] bis(Quats) were able to lyse red blood cells at very low concentrations $(0.05-0.1 \mathrm{mg} / \mathrm{L})$ [87]. Moreover, bisArgs cytotoxicity against cutaneous cells corroborates the trend observed in the haemolysis assay. The $\mathrm{IC}_{50}$ values obtained using fibroblasts range from $21.9 \mathrm{mg} / \mathrm{L}$ for $\mathrm{C}_{3}(\mathrm{LA})_{2}$ to $341 \mathrm{mg} / \mathrm{L}$ for $\mathrm{C}_{3}(\mathrm{OA})_{2}$. Similar results were obtained using keratynocytes [32].

The acute toxicity determined against $D$. magna crustaceus and bioluminescent marine bacteria $P$. phosphoreum indicated that whereas quats have $\mathrm{IC}_{50}$ and $\mathrm{EC}_{50}<1 \mathrm{ppm}$ the amino acid gemini surfactants are in the range of 2-30 ppm. Analysis of biodegradation, measured as \% total organic carbon removal, showed that these gemini surfactants with 
a spacer chain of 3 to 6 carbon atoms are readily biodegradable [88]. The degradation of these surfactants yielded fatty acids, alkyldiamine, and amino acids, none of which are hazardous from either the toxicological or ecological standpoint.

\section{Other Applications}

Cationic surfactants from amino acids, easily prepared from renewable raw materials, have a myriad of applications besides that of antimicrobial agents, due to their surface activity. In an attempt to explore the potential uses of arginine-glycerol-based compounds in clinical settings, a formulation strategy to decrease their cytotoxicity was developed. The most likely option was to tune their charge density by formulation with phosphatidylglycerol (PG) as catanionic vesicles and with dipalmitoyl phosphatidylcholine (DPPC) as cationic vesicles. Formulating the compounds 1212R, 1414R, 1212RAc and 1414RAc (series 35, 36) as negatively charged catanionic vesicles drastically reduced their cytotoxicity [89].

Even today, Gram-negative sepsis is an important health problem with high mortality. The absence of specific and effective therapy can result in septic shock. Sunil et al. studied whether bisArgs $\mathrm{C}_{3}(\mathrm{LA})_{2}$ and $\mathrm{C}_{6}(\mathrm{LA})_{2}$ (series 43) could act as endotoxin sequestering agents. These gemini surfactants bind bacterial lipopolysaccharides (LPS) and neutralize endotoxic activity in vitro (tumor necrosis factor- $\alpha$ and nitric oxide release assays), but are cytotoxic by virtue of being membrane-active. The development of less surface-active analogues may yield potentially therapeutically useful compounds for the treatment of Gram-negative sepsis [90].

Glycerolipid surfactants from arginine are potential candidates for drug delivery. Cationic vesicles prepared with pure glycerolipidic-arginine-based surfactants or mixtures of these compounds with DPPC were found to be stable, and the average diameter of the vesicles decreased with increasing alkyl chain length. These vesicles were able to encapsulate drugs such as Ciprofloxacin and 5-Fluorouracil (5-FU),. The percentage of encapsulated drug depended on the physicochemical properties of the vesicle size and the nature of the drug. The in vitro release from these formulations was delayed with respect to the corresponding free drug solutions. It was observed that these cationic vesicles showed antimicrobial activity. Moreover the ciprofloxacin encapsulated in these vesicles preserved its antimicrobial activity. Interestingly, these formulations showed two pharmacological functions: one related to the nature of the 
encapsulated drugs and the other related to the innate antibacterial properties of the surfactant-based carriers [91].

An important factor for surfactant application in living systems is the kinetics of adsorption. The rate of adsorption of insoluble phospholipids at surfaces is slow and depends on their state of dispersion. Small vesicles reduce surface tension faster than bigger and multilayered structures. A strong synergistic adsorption was found after the addition of small amounts of 1414RAc (series 36) to DPPC [92].

A synergistic formulation between the cationic amino acid surfactant MKM (series 6) and the hyaluronic acid (HA) biopolymer was developed to be used as a coating for viscose fabric $(\mathrm{CV})$. The interaction studies showed that the MKM and HA formed a complex with a slightly positive charge at neutral $\mathrm{pH}$ due to the excess of MKM to HA binding sites.

The precipitated complex adsorbs to the fabric to a greater extent than HA or MKM individually, and remains on the fabric surface even after rinsing. The samples of CV treated only with HA or MKM showed a reduction rate of pathogenic microorganisms similar to the pre-treated $\mathrm{CV}$ because the coating was washed out during the rinsing step. However, samples treated with the HA-MKM complex exhibited excellent antimicrobial properties against Gram-positive and Gram-negative bacteria and fungi (Table 15). These kinds of functionalized fibers could find applications in several fields as wound-healing and medical textiles [93].

\section{TABLE 15}

Additionally, the disulphide bond constitutes a potential reactive group able to react with thiol groups of reduced keratin fibers by a thiol/disulphide interchange reaction, providing a covalently bound substrate for the attachment of anionic dye molecules [94]. Gemini cationic surfactants based on cystine and cystamine (series 42) have been reported as amphiphilic molecules specifically designed to permanently affect keratin fibers by an adsorption/reaction process. The effectiveness of this NN'-bis (N dodecylN,N-dimethyl) cystamine glycine dihydrochloride (42, DABC) was assessed on wool fabric by scanning electron microscopy; after treatment with DABC, the wool fibers remained free/clean of bacteria, both $S$. aureus and E. coli, as shown in Figure 22. The treated fabric acquired a new property, inhibiting bacterial growth by $99.9 \%$ and $99.6 \%$, respectively [95]. 
Recently, cationic colloidal systems of $\mathrm{Cn}(\mathrm{XA})_{2}$ (series 43) surfactants and membrane additive compounds such as dilauroyl phosphatidyl choline or cholesterol have been studied. Formulations prepared with pure $\mathrm{Cn}(\mathrm{XA})_{2}$ or $\mathrm{Cn}(\mathrm{XA})_{2} / \mathrm{DLPC}$ mixtures contain big cationic aggregates with positive zeta-potential and high colloidal stability. It appears that the antimicrobial activity greatly depends on aggregate size, increasing as the size diminished [82].

Cationic amino acid-based surfactants, particularly gemini compounds, are perfect candidates for biomedical applications that require positively charged amphiphiles. In fact, most of the compounds described in the literature have been prepared and used as new synthetic vectors in gene transfection [96].

\section{Conclusions}

Cationic surfactants based on amino acids can show excellent antimicrobial and antifungical properties. The manufacturing cost of these compounds is economically viable and, in general, these kinds of surfactants can be considered as readily biodegradable compounds. Their antimicrobial activity depends on the hydrophilic/lipophilic balance of the molecule, the cationic charge density and the amino acid sequence on the polar head. Given their physicochemical and biological properties these compounds are good candidates to be used as antimicrobial compounds in biomedical and biotechnological applications.

\section{Acknowledgements}

The authors would like to generously thank the Spanish Plan National I+D+I MAT2012-38047-C02-02, MIMECO-CTQ2013-41514-P and MIMECO-CTQ201459632-R .

\section{References}

[1] a) Levy SB, Marshall B, Nat. Med., 2004; 10: 122. b) Davis J, Davis D, Microbiol. Mol. Biol. Rev. 2010; 74: 417.

[2] Weinstein RA, Emerg. Infect. Dis,. 2001; 7: 188.

[3] Cosgrove SE, Sakoulas G, Perencevich EN., Schwaber M J, Karchmer AW, Carmeli Y, Clin. Infect. Dis., 2003; 36: 53. 
[4] Zasloff M, Nature, 2002; 415: 389, b) Giuliani A, Pirri G, Nicoletto SF, Cen Eur J Biol. 2007; 2: 1 .

[5] Dathe M, Schümann M, Wieprecht T, Winkler A, Beyermann M, Krause E, Matsuzaki K, Murase O. and Bienert M, Biochemistry, 1996; 35: 1261. b) Wieprecht T, Dathe M, Epand RM, Beyermann M, Krause E, Lee Maloy W, MacDonald DL. and Bienert M, Biochemistry, 1997; 36: 12869. c) Wolf ., Pritz S, Abes S, Bienert M, Lebleu B, Oehlke J, Biochemistry, 2006; 45: 14944. d) Chongsiriwatana NP, Patch JA, Czyzewski AM, Dohm MT, Ivankin A, Gidalevitz D, Zuckermann RN, Barron AE, Proc. Natl. Acad. Sci. U.S.A, 2008; 105: 2794.

[6] Makovitzki A, Avrahami D, Shai Y, Proc. Natl. Acad. Sci. U.S.A., 2006; 103, 15997. b) Avrahami D, Shai Y, J. Biol. Chem., 2004; 279: 12277.

[7] Latham PW, Nat. Biotechnol., 1999; 17: 755.

[8] Jerala R, Expert Opin. Invest. Drugs, 2007; 16: 1159. b) Straus SK, Hancock RE, Biochim. Biophys. Acta, 2006; 1758: 1215. c) Jung D, Rozek A, Okon M, Hancock RE, Chem Biol., 2004; 11: 949. d) Epand RM, Biopolymers, 1997; 43: 15. e) Toniolo C, Crisma M, Formaggio F, Peggion C, Epand RF, Epand RM, Cell Mol Life Sci, 2001; 58: 1179. f) Avrahami D, Shai Y, Biochemistry, 2003; 42: 14946. b) Lohan S, Cameotra SS, Bisht GS, Chem. Biol. Drug Des, 2013; 82: 557.

[9] Makovitzki A, Avrahami D, Shai Y, Proc Natl Acad Sci USA, 2006; 103: 15997.

[10] Jennings M C, Minbiole KPC, Wuest WM, ACS Infect Dis, 2015, 1 (7): 288.

[11] a) Shalel S, Streichman S, Marmur A, J. Colloid Interface Sci, 2002; 252: 66. b) Funasaki N, Ohigashi M, Hada S, Neya S, Langmuir, 2000; 16: 383. c) Vieira DB, Carmona-Ribeiro AM, J. Antimicrob. Chemother, 2006; 58: 760.

[12] a) Nalecz-Jawecki G, Granbinska-Sota E, Narkiewicz P, Ecotoxicology and Environmental Safety, 2003; 54: 87. b) Garcia MT, Ribosa I, Guindulian T, Sanchez-Leal J, Vives-Rego J, Envirom. Pollut, 2001; 111: 169.

[13] Henderson ND, A review of the environmental impact and toxic effects of DDAC, Environmental Protection Division, BC Environment, Mynistry of Environment 1992; Land and Parks, Victoria, British Columbia.

[14] Salick DA, Kretsinger JK, Pochan DJ, Schneider JP, J. Am. Chem. Soc., 2007; 129: 14793.

[15] Castillo JA, Clapés P, Infante MR, Comas J, Manresa A, J. Antimicrob. Chemother, 2006; 57: 691.

[16] Makovitzki A, Shai. Y, Biochemistry, 2005; 44: 9775.

[17] Gibson H, Holah JT, In F.F. Morpeth, ed., Preservation of Surfactant Formulations, Blackie Academic and Professional, Glasgow, 1995, Ch. 3.

[18] Morán MC, Pinazo A, Pérez L, Clapés P, Angelet M, García MT, Vinardell MP, Infante MR, Green Chem, 2004; 6: 233. 
[19] Geiger R, Köning W, Amine protection groups in E. Gross and J. Meienhofer(Eds), The Peptides, Vol. 3, Academic Press, London, 1981, Chapter 1.

[20] Infante MR, Garcia Dominguez JJ, Erra P, Julià MR, Prats M, International Journal of Cosmetic Science, 1984; 6: 275.

[21] Urgell JB, Seguer J, New preservative systems and their use in cosmetic preparations, 2003; International publication number: WO 03/013454 A1

[22] Piera E, Comelles F, Erra P, Infante MR, J. Chem. Soc. Perkin Trans 2, 1998; 2: 335.

[23] Clapés P, Morán C, Infante MR, Biotech. Bioeng, 1999; 63: 333.

[24] Infante MR, Garcia Dominguez JJ, Erra P, Julià MR, Prats M, International Journal of Cosmetic Science, 1984; 6: 275.

[25] Pérez L, Pinazo A, García MT, Morán MC, Infante MR, New Journal Of Chemistry, 2004; 28 : 1326.

[26] Morán C, Clapés P, Comelles F, García T, Pérez L, Vinardell P, Mitjans M, Infante MR, Langmuir, 2001; 17: 5071.

[27] Pérez L, Pinazo A, García MT, Morán MC, Infante MR, New Journal Of Chemistry, 2004; 28: 1326.

[28] Song Y, Li Q, Li Y, Zhi L, J Surf deterg, 2014; 17: 459.

[29] Bera S, Zhanel GG, Scwhweizer F, J Antimicrob Chemother, 2010; 65: 1224.

[30] Ortega-Morente E, Fernandez-Fuentes GB, Abriouel MJ, Perez H, Pulido R, Gálvez A, Int J Food Microbiol, 2013; 162: 13.

[31] Rodriguez E, Seguer J, Rocabayera X, Manresa A, J. Appl. Microbiol, 2004; 96: 903.

[32] Pinazo A, Pérez L, Infante MR, Vinardell MP, Mitjans M, Morán MC, Martinez V, Chemical structure and toxicity in arginine-based surfactants. In: Arginine Amino Acid, Ed. Jacobs N.L. Nova biomedical, New York 2011 :125-142.

[33] Pérez L, Pinazo A, García MT, Lozano M, Manresa A, Angelet M, Vinardell MP, Mitjans M, Pons R, Infante MR, European Journal of Medicinal Chemistry, 2009; 44: 1884.

[34] Infante MR, Molinero J, Erra P, Julia MR, Garcia Dominguez JJ, Fette seifen Anstrichmittel, 1985; 87: 309.

[35] Nakamiya T, Mizuno H, Meguro T, Ryono H, Takinami K, J. Ferment. Technol, 1976; 54(6): 369.

[36] Mondal D, Zhanel GG, Schweizer F, Carbohydrate Research, 2011; 346: 588.

[37] Boullanger P, Chevalier Y, Langmuir. 1996; 12: 1771. b) Tabohashi T, Kazuhito T, Kazutami S, Junichi K., Shoko Y., Hideki S., Masahiko A, Colloids Surf. B: Biointerfaces, 2001; 20: 79. c) Goldsipe A, Blankschtein D, Langmuir, 2006; 22: 9894. d) Goldsipe A, Blankschtein D, Langmuir, 2006; $22: 3547$.

[38] Mezei A, Pérez L, Pinazo A, Comelles F, Infante MR, Pons R, Langmuir, 2012; 28: 16761. 
[39] Infante MR, Molinero J, Erra P, Julia M., García Dominguez JJ, Robert M, Fette seifen Anstrichmittel, 1986; 88: 108.

[40] Colomer A, Pinazo A, Manresa MA, Vinardell MP, Mitjans M, Infante MR, Pérez L, J. Med. Chem, 2011; 54: 989.

[41] Colomer A, Perez L, Pons R, Espuny MJ, Manresa A, Infante MR, Pinazo A, Langmuir, 2013; 29: 7912.

[42] Roy S, Das P, Biotechnology and Bioengineering, 2008; 100: 756.

[43] Dutta S, Shome A, Kar T, Das P, Langmuir, 2011; 27: 5000.

[44] Shome A, Kar T, Das P, ChemPhysChem, 2011; 12: 369 b) Roy S, Das D, Dasgupta A, Mitra R, Das P, Langmuir, 2005; 21: 10398.

[45] Shome A, Dutta S, Maiti S, Das P, Soft Matter, 2011; 7: 3011.

[46] Joondan N, Jhaumeer-Laulloo S, Caumul P, Microbiological Research, 2014; 169: 675.

[47] Sreenu M, Rao BVSK, Prasad BN, Sujitha P, Chityala GK, Eur. J. Lipid Sci. Technol, 2014; 116: 193-206.

[48] Seguer J, Molinero J, Manresa A, Caelles J, Infante MR, J. Soc. Cosmet, 1994; 45: 53.

[49] Infante MR, Molinero J, Bosch P, Julia MR, Erra P, JAOCS, 1989; 66: 1835.

[50] Gryc W, Dabrowska M, Tomicka B, Perkowska D, Kupryszewski G, Polish Journal of Chemistry, 1979; 53: 1085. b) Makovitzki A, Baram J, Shai Y, Biochemistry, 2008; 47: 10630.

[51] Makovitzki A, Baram J, Shai Y, PNAS, 2006; 103: 15997.

[52] Serrano GN, Zhanel GG, Schweizer F, Antimicrobial Agents and Chemotherapy, 2009; 53: 2215.

[53] Lohan S, Cameotra SS, Bisht GS, Chem. Biol. Drug Des, 2013; 82: 557.

[54] Mitra RN, Shome A, Paul P, Das PK, Org. Biomol. Chem, 2009; 7: 94.

[55] Joshi S, Dewangan RP, Yadav S, Rawat DS, Pasha S, Organic Biomolecular Chemistry, 2012; 10: 8326.

[56] Chan DI, Prenner EJ, Vogel HJ, Biochim. Biophys. Acta, 2006; 1758: 1184.

[57] Dougherty DA, Science, 1996; 271: 163.

[58] Yau WM, Wimley WC, Gawrisch K, White SH, Biochemistry, 1998; 37: 14713.

[59] Chan DI, Prenner EJ, Vogel HJ, Biochimica et Biophysica Acta - Biomembranes, 2006; 1758: 1184.

[60] Pérez L, Pinazo A, Vinardell P, Clapés P, Angelet M, Infante MR, New Journal of Chemistry, 2002; 26: 1221.

[61] Perez L, Infante MR, Pons R, Moran C, Vinardell P, Mitjans M, Pinazo A, Colloids and Surfaces: B Biointerfaces, 2004; 35: 235. b) Morán MC., Pinazo A, Pérez L, Clapés P, Pons R, Infante MR, Comptes Rendues Chimie, 2004; 7: 169.

[62] Israelachvili JN, Mitchel DJ, Ninham BW, Chem. Soc. Faraday Trans II, 1976; 72: 1525. 
[63] Pérez L, Infante MR, Angelet M, Clápes P, Pinazo A, Progress Colloid Polymer Science, 2004; 123: 210.

[64] Pinazo A, Pérez L, Infante MR, Pons R., Physical Chemistry Chemical Physics, 2004; 6: 1475.

[65] Tausk RJM, Karmiggelt J, Oudshoorn C, Overbeek JTG, Biophys Chem, 1974; 1: 175.

[66] Albalat R, Claret J, Ignés-Mullol J, Sagués F, Morán C, Pérez L, Clapés P, A. Pinazo, Langmuir, 2003; 19: 10878.

[67] Lozano N, Pérez L, Pons R, Luque-Ortega JR, Fernández-Reyes M, Rivas L, Pinazo A, Colloids and Surfaces A: Physicochem. Eng. Aspects 2008; 319: 196.

[68] Pinazo A, Angelet M, Pons R, Lozano M, Infante MR, Pérez L, Langmuir, 2009; 25: 7803.

[69] Pinazo A, Wen X, Pérez L, Infante MR, Franses EI, Langmuir, 1999; 15: 3134. b) Zana R, J. Colloid Interface Sci, 2002; 246: 182.

[70] Merrifield RB, J. Am. Chem. Soc., 1963; 85: 2149.

[71] Greber KE, Dawgul M, Kamysz W, Sawicki W, Lukasiak J, Amino Acids, 2014; 46: 1893.

[72] Ahn M, Murugan RN, Jacob B, Hyun JK, Cheong C, Hwang E, Park HN, Seo JH, Srinivasrao

G, Lee KS, Shin SY, Bang JK, European Journal of Medicinal Chemistry, 2013; 68: 10.

[73] Pinazo A, Diz M, Solans C, Pes MA, Erra P, Infante MR, Journal Am. Oil Chem. Soc., 1993; 70: 37.

[74] Pinazo A, Infante MR, Chang CH, Franses EI, Colloid and Surfaces A. Physico-chemical and Engineering Aspects, 1994; 87: 117.

[75] Pérez L, Torres JL, Manresa A, Solans C, Infante MR, Langmuir, 1996; 12, 5296.

[76] Piera E, Infante MR. Clapés P, Biotechnol. Bioeng, 2000; 70: 323.

[77] Pérez L, Pinazo A, Rosen MJ , Infante MR, Langmuir, 1998; 14: 2307.

[78] Colomer A, Pinazo A, Manresa MA, Vinardell P, Infante MR, Pérez L, Journal of Medicinal Chemistry, 2011; 54: 989.

[79] Tan H, Xiao H, Tetrahedron Letters, 2008; 49: 1759.

[80] Diz M, Manresa A, Pinazo A, Erra P, Infante MR, J. Chem. Soc. Perkin trans. 2, 1994; 8: 1871.

[81] Pérez L, García MT, Ribosa I, Vinardell MP, Manresa A, Infante MR, Environ. Toxicology \& Chemistry, 2002; 21: 570.

[82] Tavano L, Infante MR, Abo Riya M, Pinazo A,Vinardell MP, Mitjans M, Manresa MA, Pérez

L, Soft Matter, 2013; 9: 306.

[83] Devinsky F, Lacko I, Bittererova F, Mlynarcik D, Chem Pap, 1987; 41: 803.

[84] Ronsin G, Kirby A J, Rittenhouse S, Woodnutt G, Camilleri P, J. Chem., Soc. Perkin Trans, 2002; 2: 1302.

[85] Castillo JA, Clapés P, Infante M, Comas J, Manresa A, Journal of Antimicrobial Chemotherapy, 2006; 57: 691. 
[86] Tavano L, Infante MR, Abo Riya M, Pinazo A, Vinardell MP, Mitjans M, Manresa A, Pérez L, Soft Mather, 2013; 9: 306-319.

[87] Devinsky F, Lacko I, Bittererova F, Mlynarcik D, Chem.Pap, 1987; 41: 803.

[88] Pérez L, García MT, Ribosa I, Vinardell MP, Manresa A, Infante MR, Environ. Toxicol. Chem, 2002; $21: 1279$.

[89] Lozano N, Pérez L, Pons R, Pinazo A, Aminoacids, 2011; 40: 721.

[90] David S, Pérez L, Infante MR, Bioorg. Med. Chem. Lett., 2002; 12: 357.

[91] Tavano L, Pinazo A, Abo-Riya M, Infante MR, Manresa MA, Colloids and Surfaces B: Biointerfaces 2014; 120: 160.

[92] Lozano N, Pinazo A, Pons R, Pérez L, Franses EI, Colloids and Surfaces B: Biointerfaces, 2009; 74: 67.

[93] Bracic M, Pérez L, Infante R, Kogej K, Hribernik S, Sauperl O, Fras Zemljic L, Cellulose, 2014; $21: 2647$.

[94] Lewis DM, J. Soc Dye Color, 1990; 106: 270.

[95] Infante M, Diz M, Manresa A, Pinazo A, Erra P, Journal Appl. Bacteriology, 1996; 81: 212216.

[96] Pérez L, Pinazo A, Pons R, Infante MR, Advances in Colloid and Interface Science, 2014; 205: 134. 
Table 1. CMC, surface tension at the $\left(\gamma_{\mathrm{cmc}}\right)$, and area per molecule $\left(\mathrm{A}_{\min }\right)$ of arginine-based surfactants.

\begin{tabular}{|c|c|c|c|c|}
\hline & Compound & $\mathrm{CMC}(\mathrm{mM})$ & $\gamma_{\mathrm{cmc}}(\mathrm{mN} / \mathrm{m})$ & $A_{\min }\left(10^{2} \mathrm{~nm}^{2}\right)$ \\
\hline \multirow{5}{*}{ 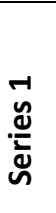 } & OAM & & & \\
\hline & CAM & 16 & 40 & 47 \\
\hline & LAM & 5.8 & 32 & 67 \\
\hline & MAM & 2.0 & 32 & 57 \\
\hline & $\operatorname{PAM}^{(1)}$ & 0.2 & 26 & 60 \\
\hline \multirow{3}{*}{ 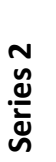 } & ACA & 26 & 35 & 62 \\
\hline & ALA & 1.8 & 37 & 90 \\
\hline & AMA & 0.7 & 33 & 114 \\
\hline \multirow{3}{*}{ 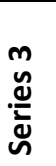 } & $\mathrm{AOE}$ & 38 & 35 & 96 \\
\hline & ACE & 13 & 40 & 72 \\
\hline & ALE & 5 & 33 & 122 \\
\hline \multirow{3}{*}{ 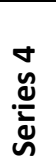 } & $\mathrm{OAS}^{(3)}$ & nd & $43.5^{(3)}$ & nd \\
\hline & $\operatorname{CAS}^{(3)}$ & nd & $35.5^{(3)}$ & nd \\
\hline & $\operatorname{LAS}^{(3)}$ & nd & $43.8^{(3)}$ & nd \\
\hline \multirow{3}{*}{ 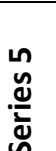 } & $100 R$ & $6^{(2)}$ & nd & nd \\
\hline & $120 \mathrm{R}$ & $1.3^{(2)}$ & nd & nd \\
\hline & $140 R$ & $0.2^{(2)}$ & nd & nd \\
\hline
\end{tabular}

(1)Due to the low solubility of this compound, the surface tension/concentration curve was determined at 40 으

${ }^{(2)} \mathrm{cmc}$ calculated from conductivity measurements.

${ }^{(3)}$ These amphoteric compounds showed very low aqueous solubility, making it impossible to determine the $\mathrm{cmc}$. The $\gamma$ values correspond to the surface tension measured at their maximum concentration of solubility. 
Table 2. Antibacterial activity based on the minimal inhibitory concentration (MIC $\mu \mathrm{g} / \mathrm{mL}$ ) of single chain arginine-based surfactants

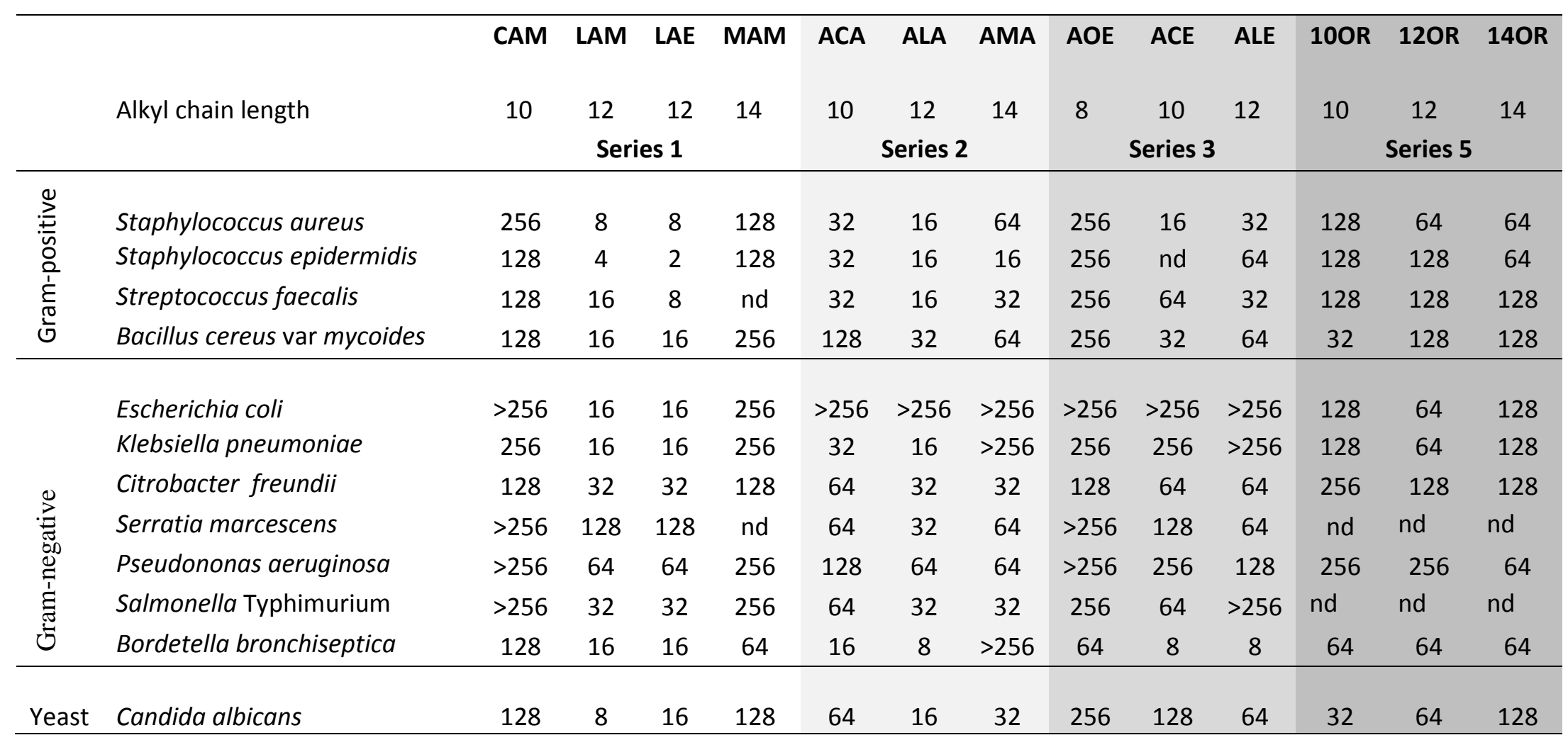


Table 3. CMC and pKa values of cationic $\mathrm{N}$-acyl-lysine surfactants

\begin{tabular}{ccccc}
\hline Compound & Alkyl chain & $\begin{array}{c}\text { Protonated amine } \\
\text { group }\end{array}$ & $\mathrm{pKa}$ & $\mathrm{CMC}$ \\
\hline LLM & $\mathrm{C}_{12}$ & $\varepsilon$ - amine & 8.8 & 7.2 \\
\hline LKM & & & & \\
MKM & $\mathrm{C}_{12}$ & $\alpha$-amine & 5.3 & 8.5 \\
PKM & $\mathrm{C}_{14}$ & & 4.5 & 3 \\
\hline
\end{tabular}


Table 4. Minimum inhibitory concentration (MIC $\mu \mathrm{g} / \mathrm{mL}$ ) of lysine-derived surfactants

\begin{tabular}{|c|c|c|c|c|c|c|c|c|c|}
\hline $\begin{array}{l}\text { Alkyl chain } \\
\text { (pKa) }\end{array}$ & $\begin{array}{c}\text { LKM } \\
\mathrm{C}_{12} \\
(6.2)\end{array}$ & $\begin{array}{c}\text { MKM } \\
\text { C }_{14} \\
(5.3)\end{array}$ & $\begin{array}{c}\text { PKM } \\
\mathrm{C}_{16} \\
(4.5)\end{array}$ & $\begin{array}{c}\text { LLM } \\
\text { C }_{12} \\
(8.8)\end{array}$ & $\begin{array}{c}\text { LLE } \\
\mathrm{C}_{12}\end{array}$ & $\begin{array}{c}\text { LLS } \\
\mathrm{C}_{12}\end{array}$ & $\begin{array}{c}\mathbf{L L M}_{\mathbf{q}} \\
\mathrm{C}_{12}\end{array}$ & $\begin{array}{c}\mathbf{L L E}_{\mathbf{q}} \\
\mathrm{C}_{12}\end{array}$ & $\begin{array}{c}\text { MKM Q }_{\mathbf{Q}} \\
\mathrm{C}_{14}\end{array}$ \\
\hline Series & 6 & 6 & 6 & 7 & 7 & 7 & 8 & 8 & 9 \\
\hline S aureus & 128 & 64 & 64 & 32 & 8 & $>128$ & 128 & 8 & 16 \\
\hline S. epidermidis & 64 & 64 & 64 & 16 & 4 & $>128$ & 32 & 4 & 8 \\
\hline Bacillus. subtilis & 125 & $64 / 16$ & 64 & 16 & 8 & $>128$ & 64 & 8 & 16 \\
\hline B. cereus var mycoides & 64 & 64 & 64 & 64 & 16 & $>128$ & 64 & 16 & \\
\hline Micrococcus luteus & 128 & $64 / 16$ & 32 & 4 & 8 & $>128$ & 32 & 8 & 16 \\
\hline Myccobacterium phlei & 64 & 32 & 64 & & & $>128$ & & & \\
\hline S. faecalis & & & & 32 & 8 & $>128$ & 64 & & \\
\hline Acinetobacter calcoaceticus & & & & 32 & 8 & $>128$ & 64 & 8 & \\
\hline Corynebacterium agropiry & & & & 4 & 2 & $>128$ & 32 & & \\
\hline E. coli & 63 & 64 & 256 & 16 & 8 & $>128$ & $>128$ & 8 & 125 \\
\hline K. pneumoniae & 125 & 128 & $>256$ & 32 & 16 & $>128$ & 64 & 16 & 125 \\
\hline S. marcescens & $>256$ & $>257$ & $>258$ & 128 & 32 & $>128$ & 128 & 32 & \\
\hline P. aeruginosa & $>256$ & $>256$ & $>256$ & 64 & 128 & $>128$ & - & 128 & $>256$ \\
\hline S. tiphymurium & $>256$ & $>256$ & $>256$ & 32 & & $>128$ & - & & \\
\hline S. derby & & & & & 32 & $>128$ & $>128$ & 128 & \\
\hline C. freundii & & & & & 32 & $>128$ & $64 / 128$ & 64 & \\
\hline B. bronchiseptica & $>256$ & $>257$ & $>258$ & 16 & 32 & $>128$ & $16 / 128$ & 64 & \\
\hline E. aerogenes & $>256$ & $>257$ & $>258$ & & & $>128$ & - & & \\
\hline C. albicans & 64 & $>256$ & $>256$ & & 32 & $>128$ & 8 & 8 & 16 \\
\hline
\end{tabular}


Table 5. Critical micellar concentration of cationic single chain surfactants from phenylalanine and tyrosine (series 17)

\begin{tabular}{ccc}
\hline $\begin{array}{c}\text { Alkyl chain } \\
(\mathrm{n})\end{array}$ & $\begin{array}{c}\text { CMC (mM) } \\
\text { Phenylalanine compounds }\end{array}$ & $\begin{array}{c}\text { CMC (mM) } \\
\text { Tyrosine compounds }\end{array}$ \\
\hline 7 & 3.96 & 1.94 \\
9 & 0.69 & 0.28 \\
11 & 0.15 & 0.039 \\
13 & 0.018 & 0.014 \\
15 & 0.014 & \\
17 & 0.011 & \\
19 & 0.007 & \\
\hline
\end{tabular}


Table 6. CMC and surface tension at the $\mathrm{cmc}\left(\gamma_{\mathrm{cmc}}\right)$ corresponding to the long-chain $\mathrm{N}^{\alpha}$ acyl-L-arginine diamino acid surfactants

\begin{tabular}{lccc}
\hline & Compound & CMC $(\mathrm{mM})$ & $\gamma_{\mathrm{cmc}}(\mathbf{m N} / \mathbf{m})$ \\
\hline Cationic & LAGOM & $\mathbf{6 . 5}$ & $\mathbf{3 7 . 6}$ \\
& LAPOM & $\mathbf{1 . 5}$ & $\mathbf{3 4 . 6}$ \\
& LALM & $\mathbf{2 5 *}$ & nd \\
& LAKM & $\mathbf{2 6} *$ & nd \\
& LKKM & $\mathbf{2 2 *}$ & nd \\
\hline Amphoteric & LAGOH & $\mathbf{1 . 5}$ & $\mathbf{3 0 . 0}$ \\
& LAPOH & $\mathbf{0 . 2 5}$ & $\mathbf{3 0 . 0}$ \\
\hline Mixtures & $\mathrm{C}_{8} \mathrm{AC}$ & $\mathbf{2 . 1}$ & $\mathbf{3 5}$ \\
& $\mathrm{C}_{10} \mathrm{AC}$ & $\mathbf{0 . 4 9}$ & $\mathbf{3 3}$ \\
& $\mathrm{C}_{12} \mathrm{AC}$ & $\mathbf{0 . 1 9}$ & $\mathbf{3 2}$ \\
& $\mathrm{C}_{14} \mathrm{AC}$ & $\mathbf{0 . 0 7 1}$ & $\mathbf{2 8}$ \\
& $\mathrm{C}_{16} \mathrm{AC}$ & $\mathbf{0 . 0 3 4}$ & $\mathbf{2 9}$
\end{tabular}

*cmc calculated by conductivity measurements 
Table 7. Antimicrobial activity based on the MIC values $(\mu \mathrm{g} / \mathrm{mL})$ of cationic and amphoteric $\mathbf{N}$-acyl-arginine-amino acid surfactants

\begin{tabular}{|c|c|c|c|c|c|c|c|c|c|c|}
\hline & LAGOM & LAGuOM & LAPOM & LALM & LAKM & LKKM & LAGOH & LAGuOH & LAPOH & LALOH \\
\hline & \multicolumn{3}{|c|}{ Cationic } & \multicolumn{3}{|c|}{ Cationic } & \multicolumn{4}{|c|}{ Amphoteric } \\
\hline B.subtilis & 16 & $>$ & 16 & 28 & 218 & 115 & 16 & $>$ & 4 & 128 \\
\hline S. epidermis & 16 & $>$ & 4 & 218 & 436 & 115 & 16 & $>$ & 4 & $>$ \\
\hline M. luteus & 32 & 64 & 8 & 28 & 436 & 115 & 16 & $>$ & 2 & 128 \\
\hline C. albicans & 32 & 128 & 16 & 218 & 436 & $\mathrm{R}$ & 32 & $>$ & 4 & $>$ \\
\hline P.aeruginosa & 128 & $>$ & 256 & 218 & $\mathrm{R}$ & 459 & $>$ & $>$ & $>$ & $>$ \\
\hline K. pneumoniae & $>$ & $>$ & 256 & 218 & $\mathrm{R}$ & 459 & $>$ & $>$ & $>$ & $>$ \\
\hline E. coli & 32 & 128 & 16 & 218 & $\mathrm{R}$ & 229 & 16 & $>$ & 4 & $>$ \\
\hline
\end{tabular}


Table 8. CMC values obtained by different techniques for compounds XXR and XXRAc.

\begin{tabular}{cccc}
\hline Compound & Surface Tension $(\mathrm{mM})$ & $\begin{array}{c}\text { Conductivity } \\
(\mathrm{mM})\end{array}$ & $\begin{array}{c}\text { Fluorescence } \\
(\mathrm{mM})\end{array}$ \\
\hline $88 \mathrm{R}$ & $0.07^{\mathrm{a}}$ & $5^{\mathrm{a}}$ & $7^{\mathrm{a}}$ \\
$1010 \mathrm{R}$ & $0.006^{\mathrm{b}}$ & $1.1 \mathrm{a}$ & $0.3^{\mathrm{a}}$ \\
$1212 \mathrm{R}$ & $0.008^{\mathrm{a}}$ & $0.3^{\mathrm{a}}$ & \\
$1414 \mathrm{R}$ & & $0.25^{\mathrm{a}}$ & \\
1212RAc & & $0.12^{\mathrm{b}}$ & \\
1414RAc & $0.002-0.008^{\mathrm{b}}$ & $0.09^{\mathrm{b}}$ & \\
\hline
\end{tabular}

${ }^{\mathrm{a}}$ From reference [64], ${ }^{\mathrm{b}}$ From reference [62a] 
Table 9. MIC values (mg/L) corresponding to arginine diacyl-glycerolipid conjugates and the lysine bisglycidol derivative.

\begin{tabular}{lccccccc}
\hline MICROORGANISMS & $88 \mathrm{R}$ & $1010 \mathrm{R}$ & $1212 \mathrm{R}$ & $1414 \mathrm{R}$ & $1212 \mathrm{RAc}$ & 1414RAc & LGGdi12 \\
\hline B. cereus var.mycoides & 64 & 16 & $>256$ & $>256$ & 4 & $>256$ & 128 \\
S. epidermis & 8 & $>256$ & $>256$ & 16 & $>256$ & 8 & 128 \\
M. luteus & 16 & 1 & 4 & 1 & 2 & 4 & 128 \\
S. aureus & 4 & 16 & $>256$ & 256 & 32 & 32 & 64 \\
B. subtilis & 64 & 2 & $>256$ & $>256$ & 32 & $>256$ & 32 \\
Arthrobacter oxidans & 32 & 16 & $>256$ & $>256$ & - & - & \\
S. faecalis & 8 & 4 & 2 & 0.5 & - & - & \\
\hline S. Typhimurium & 16 & 32 & $>256$ & $>256$ & 32 & $>256$ & 256 \\
P. aeuriginosa & 64 & $>256$ & $>256$ & $>256$ & $>256$ & $>256$ & 256 \\
E. coli & 8 & 64 & $>256$ & $>256$ & $>256$ & $>256$ & 128 \\
B. bronchiseptica & 0.25 & 0.25 & 0.25 & 0.25 & $>256$ & $>256$ & 32 \\
C. freundii & 32 & $>256$ & $>256$ & 256 & $>256$ & $>256$ & \\
A. faecalis & 8 & 4 & $>256$ & 256 & 16 & 2 & - \\
Enterobacter aerogenes & 32 & $>256$ & $>256$ & 16 & 32 & 32 & $>256$ \\
K. pneumonie v. preumonial & 8 & 16 & $>256$ & 4 & 8 & 1 & 128 \\
\hline C. albicans & 16 & 32 & 64 & $>256$ & $>256$ & 8 & 128 \\
\hline
\end{tabular}


Table 10. CMC of series 40 surfactants

\begin{tabular}{ccc}
\hline Compound & $\mathrm{CMC}(\mathrm{mM})$ & $\gamma \mathrm{CMC}(\mathrm{mN} / \mathrm{m})$ \\
\hline & & \\
$\left(\mathrm{C}_{8}\right)_{2}-\mathrm{KKKK}^{-} \mathrm{NH}_{2}$ & 6.8 & 43.5 \\
$\left(\mathrm{C}_{10}\right)_{2}-\mathrm{KKKK}_{2} \mathrm{NH}_{2}$ & 1.76 & 43.8 \\
$\left(\mathrm{C}_{12}\right)_{2}-\mathrm{KKKKK}_{2} \mathrm{NH}_{2}$ & 0.66 & 45.1 \\
$\left(\mathrm{C}_{14}\right)_{2}-{\mathrm{KKKKK}-\mathrm{NH}_{2}}$ & 0.16 & 46.8 \\
\hline
\end{tabular}


Table 11. Adsorption properties of bisArgs $\mathrm{C}_{n}(\mathrm{XA})_{2}$ as a function of the spacer chain length in water at $25^{\circ} \mathrm{C}$. Values in brackets correspond to conductivity data from Pinazo et al. ${ }^{69}$ The cmc of the monocatenary LAM has been also included.

\begin{tabular}{cccccc}
\hline Surfactant & CMC $(\mu \mathrm{M})$ & $\begin{array}{c}\gamma_{\mathrm{CMC}} \\
(\mathrm{mN} / \mathrm{m})\end{array}$ & Surfactant & $\mathbf{C M C}(\boldsymbol{\mu M})$ & $\begin{array}{c}\gamma_{\mathrm{CMC}} \\
(\mathrm{mN} / \mathrm{m})\end{array}$ \\
\hline $\mathrm{C}_{2}(\mathrm{LA})_{2}$ & 9.5 & 30 & $\mathrm{C}_{2}(\mathrm{CA})_{2}$ & $\mathbf{5 8}$ & 33 \\
$\mathrm{C}_{3}(\mathrm{LA})_{2}$ & $4.4(500)$ & 35 & $\mathrm{C}_{3}(\mathrm{CA})_{2}$ & $\mathbf{4 3}$ & 32 \\
$\mathrm{C}_{4}(\mathrm{LA})_{2}$ & 2.8 & 30 & $\mathrm{C}_{4}(\mathrm{CA})_{2}$ & $\mathbf{4 8}$ & 33 \\
$\mathrm{C}_{6}(\mathrm{LA})_{2}$ & $1.3(400)$ & 30 & $\mathrm{C}_{6}(\mathrm{CA})_{2}$ & $\mathbf{2 1}$ & 33 \\
$\mathrm{C}_{9}(\mathrm{LA})_{2}$ & $2.8(300)$ & 34 & $\mathrm{C}_{9}(\mathrm{CA})_{2}$ & $\mathbf{1 6}$ & 35 \\
$\mathrm{C}_{10}(\mathrm{LA})_{2}$ & 1.9 & 34 & $\mathrm{C}_{10}(\mathrm{CA})_{2}$ & $\mathbf{7 . 3}$ & 36 \\
$\mathrm{LAM}$ & $6000(6000)$ & 33 & & & \\
\hline
\end{tabular}


Table 12. MIC values of $C_{n}(X A)_{2}$. Influence of the spacer on antimicrobial activity.

\section{Gemini Surfactants}

\begin{tabular}{lcccccc}
\hline & $\begin{array}{l}\mathbf{C}_{2}(\mathbf{C A})_{2} \\
(\mu \mathbf{g} / \mathbf{m L})\end{array}$ & $\begin{array}{c}\mathbf{C}_{\mathbf{3}}(\mathbf{C A})_{2} \\
(\mu \mathbf{g} / \mathbf{m L})\end{array}$ & $\begin{array}{c}\mathbf{C}_{\mathbf{4}}(\mathbf{C A})_{2} \\
(\mu \mathbf{g} / \mathbf{m L})\end{array}$ & $\begin{array}{c}\mathbf{C}_{6}(\mathbf{C A})_{2} \\
(\mu \mathbf{g} / \mathbf{m L})\end{array}$ & $\begin{array}{c}\mathbf{C}_{9}(\mathbf{C A})_{2} \\
(\mu \mathbf{g} / \mathbf{m L})\end{array}$ & $\begin{array}{c}\mathbf{C}_{10}(\mathbf{C A})_{2} \\
(\mu \mathbf{g} / \mathbf{m L})\end{array}$ \\
\hline B. subtilis & 32 & 64 & 64 & 64 & 128 & 32 \\
S. epidermis & 64 & 8 & 128 & 64 & 128 & 128 \\
M. luteus & 32 & 32 & 8 & 8 & 32 & 16 \\
S. aureus & 32 & 8 & 64 & 64 & 64 & 16 \\
\hline C. albicans & 8 & 16 & 32 & 16 & 32 & 32 \\
\hline P. aeruginosa & 64 & 64 & 64 & 64 & 128 & $>128$ \\
K. pneumoniae & 32 & 16 & 16 & 16 & 32 & 128 \\
E. coli & $>128$ & 64 & 16 & 64 & 32 & $>128$ \\
\hline
\end{tabular}


Table 13. MIC values of $\mathrm{C}_{\mathrm{n}}(\mathrm{XA})_{2}$. Influence of the alkyl chain length on antimicrobial activity.

\begin{tabular}{|c|c|c|c|}
\hline \multicolumn{4}{|c|}{ Gemini Surfactants } \\
\hline & $\begin{array}{c}\text { C3(LA)2 } \\
(\mu \mathrm{g} / \mathrm{mL})\end{array}$ & $\begin{array}{c}\text { C3(CA)2 } \\
(\mu \mathrm{g} / \mathrm{mL})\end{array}$ & $\begin{array}{c}\text { C3(OA)2 } \\
(\mu \mathrm{g} / \mathrm{mL})\end{array}$ \\
\hline B.subtilis & 4 & 64 & 256 \\
\hline S. epidermis & $>128$ & 8 & 32 \\
\hline M. luteus & 8 & 32 & - \\
\hline S. aureus & 64 & 8 & 256 \\
\hline C. albicans & 16 & 16 & 128 \\
\hline P.aeruginosa & $>128$ & 64 & 256 \\
\hline $\begin{array}{l}\text { K. } \\
\text { pneumoniae }\end{array}$ & 8 & 16 & 256 \\
\hline E. coli & $>128$ & 64 & $>256$ \\
\hline
\end{tabular}


Table 14. Influence of the type of cationic charge (trimethylated, guanidine group, $\alpha$ amine group and $\varepsilon$-amino group of the lysine) on antimicrobial activity.

\begin{tabular}{|c|c|c|c|c|c|}
\hline & & \multicolumn{4}{|c|}{ Gemini Surfactants } \\
\hline & $\begin{array}{c}\mathbf{C}_{6}(\mathbf{L A})_{2} \\
(\mu \mathrm{g} / \mathrm{mL}) \\
\mathrm{pKa}=10.5\end{array}$ & $\begin{array}{l}\mathbf{C}_{6}(\mathbf{L L})_{2} \\
(\mu \mathbf{g} / \mathbf{m L}) \\
\mathrm{pKa}=8.2 \\
\end{array}$ & $\begin{array}{l}\mathbf{C}_{6}(\mathbf{L K})_{2} \\
(\mu \mathrm{g} / \mathbf{m L}) \\
\mathrm{pKa}=6.8\end{array}$ & $\begin{array}{c}\mathrm{C}_{7} \mathbf{N H}(\mathbf{L K})_{2} \\
(\mu \mathrm{g} / \mathbf{m L}) \\
\mathrm{pKa}=6.9 \\
\end{array}$ & $\begin{array}{c}\mathbf{C}_{6}(\mathbf{L K})_{2 \mathbf{Q}} \\
(\mu \mathrm{g} / \mathbf{m L}) \\
\text { Fixed charge }\end{array}$ \\
\hline B.subtilis & 8 & 250 & 250 & 125 & 15 \\
\hline S. epidermis & $\mathrm{R}$ & 63 & 31 & 125 & 15 \\
\hline M. luteus & 16 & 125 & $\mathrm{R}$ & 125 & 60 \\
\hline S. aureus & 8 & 125 & $\mathrm{R}$ & $\mathrm{R}$ & 60 \\
\hline C. albicans & 16 & $\mathrm{R}$ & $\mathrm{R}$ & 250 & 60 \\
\hline $\begin{array}{l}\text { P.aeruginosa } \\
K \text {. }\end{array}$ & $\begin{array}{l}\mathrm{R} \\
8\end{array}$ & $\mathrm{R}$ & $\mathrm{R}$ & 125 & $\mathrm{R}$ \\
\hline pneumoniae & & $\mathrm{R}$ & $\mathrm{R}$ & $\mathrm{R}$ & $\mathrm{R}$ \\
\hline E. coli & $\mathrm{R}$ & 250 & $\mathrm{R}$ & $\mathrm{R}$ & $\mathrm{R}$ \\
\hline
\end{tabular}


Table 15. Reduction of pathogenic microorganisms (in \%) for solutions of MKM, pretreated CV and functionalised CV (CV-MKM-HA)

\begin{tabular}{lccccc}
\hline Sample & $\begin{array}{c}\text { \% Reduction } \\
\text { S. aureus }\end{array}$ & E. coli & S. agalactiae & C. albicans & $\begin{array}{c}\text { Candida. } \\
\text { glabrata }\end{array}$ \\
\hline MKM & 62 & 43 & 59 & 83 & 66 \\
CV & 20 & 18 & 72 & 20 & 58 \\
CV-MKM-HA & 98 & 100 & 100 & 100 & 100 \\
\hline
\end{tabular}




\section{Figure captions}

Figure 1. Different routes for the preparation of single chain amino acid surfactants

Figure 2. Chemical structure of single chain arginine-based surfactants.

Figure 3. Chemical structure of single chain lysine-based surfactants.

Figure 4. Chemical structure of modified single chain lysine-based surfactants.

Figure 5.Transmission electron micrography of (a) S. aureus control cells and (b) S. aureus treated with LLM at MIC for $30 \mathrm{~min}$ at $25^{\circ} \mathrm{C}$ (c) E. coli cells treated with LLM at MIC for $30 \mathrm{~min}$ at $25^{\circ} \mathrm{C}$ and (d) E.coli control.

Figure 6. Structure of single chain tryptophan and tyrosine surfactants.

Figure 7. Cationic single chain surfactants from phenylalanine and tyrosine

Figure 8. Chemical structure of monocatenary surfactants with two amino acids on the polar head.

Figure 9. N $\alpha$-acyl-lysine surfactants with a varying number of lysine residues on the polar head.

Figure 10. Na-acyl-ornithine surfactants with a varying number of lysine residues on the polar head.

Figure 11. Chemical structure of antimicrobial dipeptide-based amphiphiles

Figure 12. a) Structure of a phospholipid, b) Structure of XXR compounds, 88R $n=5$, 1010R $n=7,1212 \mathrm{R} \mathrm{n}=9,1414 \mathrm{R} n=11$, c) Structure of XXRAc compounds, 1212RAc $\mathrm{n}=9,1414 \mathrm{RAc} \mathrm{n}=11$.

Figure 13. Schematic structure of $\mathrm{N} \varepsilon, N \varepsilon^{\prime}$-bis( $\eta$-acyloxypropyl)-L-lysine methyl ester salts.

Figure 14. Structure of L-lysine surfactants, $(\mathrm{Cx}) 2-\mathrm{KKKK}-\mathrm{NH} 2(\mathrm{R}=\mathrm{C} 8, \mathrm{C} 10, \mathrm{C} 12$, C14 and C16).

Figure 15. Chemical structure of single chain and double chain histidine-based surfactants.

Figure 16. Chemical structure of $\mathrm{N} \alpha, \mathrm{N} \alpha^{\prime}$-bis( $\mathrm{N}$-dodecyl $\mathrm{N}, \mathrm{N}$-dimethylglycine) cystine dimethyl ester dihydrochloride, DABC

Figure 17. General formula for $\mathrm{Cn}(\mathrm{XA}) 2$ compounds.

Figure 18. Chemical structure of gemini lysine-based surfactants

Figure 19. Chemical structure of asymmetric cationic gemini surfactants from lysine

Figure 20. Dual staining of Staphylococcus aureus ATCC (a, control culture; b, treated population) and Escherichia coli (c, control culture; d, treated population) stained with 
propidium iodure and SYTO-13 after exposure to $\mathrm{C} 3(\mathrm{CA}) 2$ at 2/3 MIC concentration for $30 \mathrm{~min}$ (ref.93).

Figure 21. Effect of the lysine-based surfactant C6(LL)2 on Staphylococcus aureus ATCC 25178 (a, control culture; b, treated population) and Escherichia coli ATCC 27325 (c, control culture, d, treated population). Time of contact $30 \mathrm{~min}$. at MIC.

Figure 22. Scanning electron micrographs of wool fabric. Untreated sample and treated samples with E. coli and S. aureus. 
<smiles>[R]C(NC(=O)C(C)(C)C)C(=O)O</smiles>

$\mathrm{N}^{\alpha}$-acyl amino acid<smiles>[R]C(N)C(=O)OC(C)(C)C</smiles>

$\mathrm{O}^{\alpha}$-ester amino acid<smiles>[R]C(N)C(=O)NC(C)(C)C</smiles>

Figure 1. 
<smiles>[R]OC(=O)C(CCCNC(=N)[ClH+])NC(=O)C1(C)CC1(C)C</smiles>

\section{Series 1}

$\mathrm{N}^{\alpha}$-acyl arginine alkyl ester hydrochloride $\mathrm{R}=\mathrm{CH} 3$ and $\mathrm{n}=8 \mathrm{CAM}, \mathrm{n}=10$ LAM, $\mathrm{n}=12$ MAM $\mathrm{n}=14$ PAM $\mathrm{R}=\mathrm{CH} 2-\mathrm{CH} 3$ and $\mathrm{n}=10 \mathrm{LAE}$<smiles>N=C([Cl+])NCCCC([NH3+])C(=O)OC12CCC(CC1)C2</smiles>

Series 3

Arginine O-alkyl ester dihydrochloride $n=7$ AOE, $n=9$ ACE, $n=11$ ALE<smiles>CC1(NC(=O)C(CCCNC(=N)[Cl+])[N]Cl)CC2CC1C2</smiles>

\section{Series 2}

Arginine $\mathrm{N}$-alkyl amide dihydrochloride $n=9$ ACA, $n=11$ ALA, $n=13$ AMA<smiles>CC12CCC(C)(C(=O)NC(CCCNC(=N)[Cl+])C(=O)[OH2+])C1C2</smiles>

Series 4

Sodium salt of $\mathrm{N}^{\alpha}$-acyl arginine hydrochloride $n=6$ OAS, $n=8$ CAS, $n=10$ LAS<smiles>N=C([Cl+])NCCCC([NH3+])C(=O)OCC(O)COC(=O)C12CCC(CC1)C2</smiles>

Series 5

1 acyl-rac-glycero-3-O-(L-arginine) dihydrochloride $\mathrm{n}=8$ 100R, $\mathrm{n}=10$ 120R, $\mathrm{n}=12$ 140R

Figure 2 


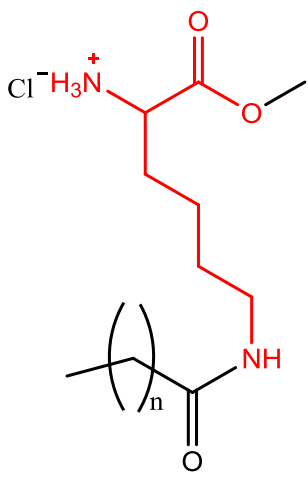

Series 6

$\mathrm{N}^{\varepsilon}$-acyl-lysine methyl ester $n=10$ LKM; n=12 MKM; n=14 PKM

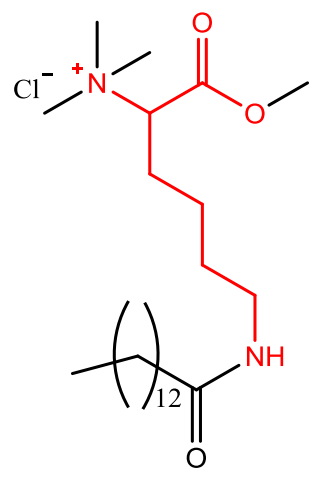

Series 9

$\mathrm{N}^{\alpha}$-Miristoyl-Ne-trimethyl-lysine methyl ester (MKM $)$<smiles>[X]OC(=O)C(CCCC[NH3+])NC(=O)C1(C)CC2(C)CC1C2</smiles>

Series 7

a) $\mathrm{X}=\mathrm{CH} 3 \quad \mathrm{~N}^{\alpha}$-Lauroyl-lysine methyl ester (LLM) b) $\mathrm{x}=\mathrm{CH} 2-\mathrm{CH} 3 \mathrm{~N}^{\alpha}$-Lauroyl-lysine methyl ester(LLE) c) $\mathrm{X}=\mathrm{Na}$ Sodium salt of $\mathrm{N}^{\alpha}$-Lauroyl-lysine(LLS)<smiles>[X]OC(=O)C(CCCC[N+](C)(C)C)NC(=O)C1(C)CCC2(C)CC1C2</smiles>

Series 8

a) $\mathrm{X}=\mathrm{CH} 3 \quad \mathrm{~N}^{\alpha}$-Lauroyl- $\mathrm{N}^{\varepsilon}$-trimethyl-lysine methyl ester (LLM)

b) $\mathrm{x}=\mathrm{CH} 2-\mathrm{CH} 3 \mathrm{~N}^{\alpha}$-Lauroyl-N $\mathrm{N}^{\varepsilon}$-trimethyl-lysine ethyl ester (LLM)。<smiles>[R]C(N[Cl+]Cl)C(=O)OC1(C)CC1(C)C</smiles>

Series 10

$\mathrm{R}=$ lateral alkyl chain of glycine, Valine, Proline, Phenylalanine,

Tryptophan, Lysine, and arginine<smiles>CC1(C)CC(C)(NC(=O)C(CCCC[NH3+])[NH2+]Cl)C1</smiles>

Series 11

\section{Figure 3}




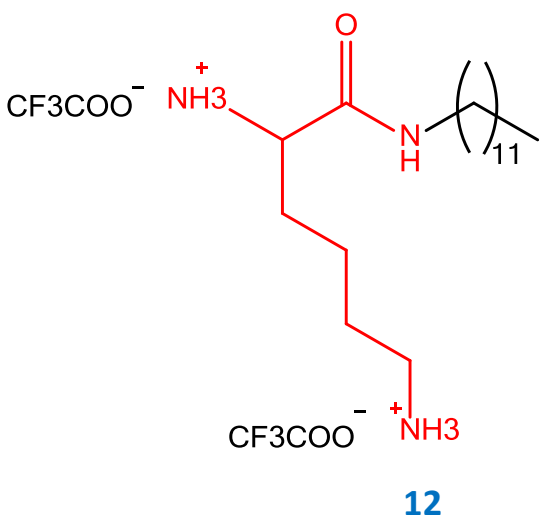

Lauroyl amide of lysine dihydrochloride

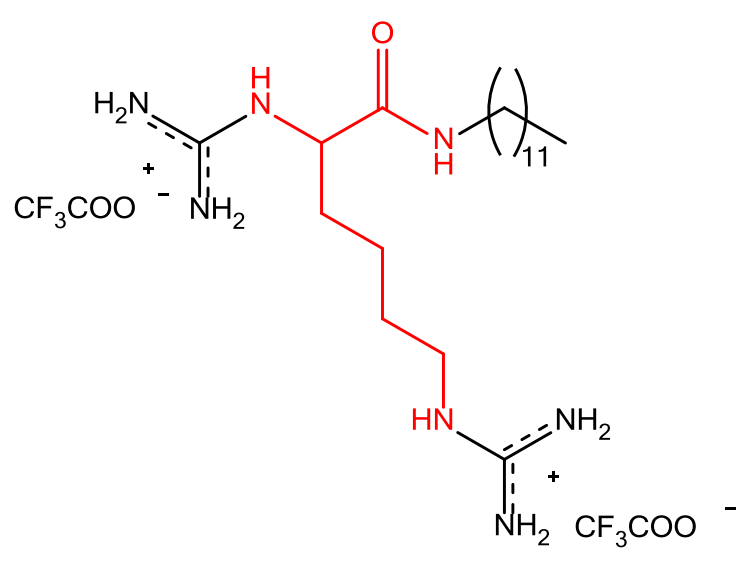

13

Guanidinylated lauroyl amide of lysine dihydrochloride

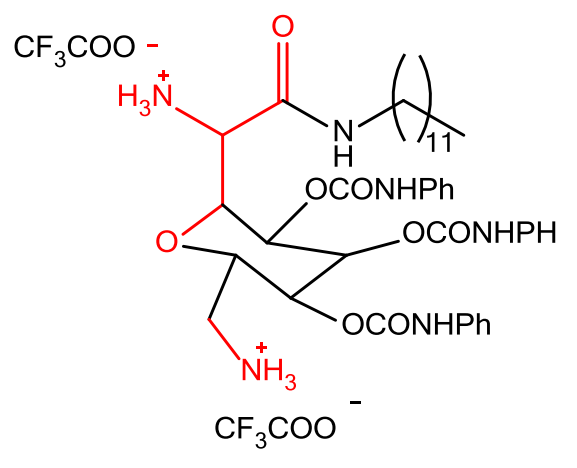

14

Polyol modified carbohydrate-template lauroyl amide of lysine dihydrochloride

Figure 4 


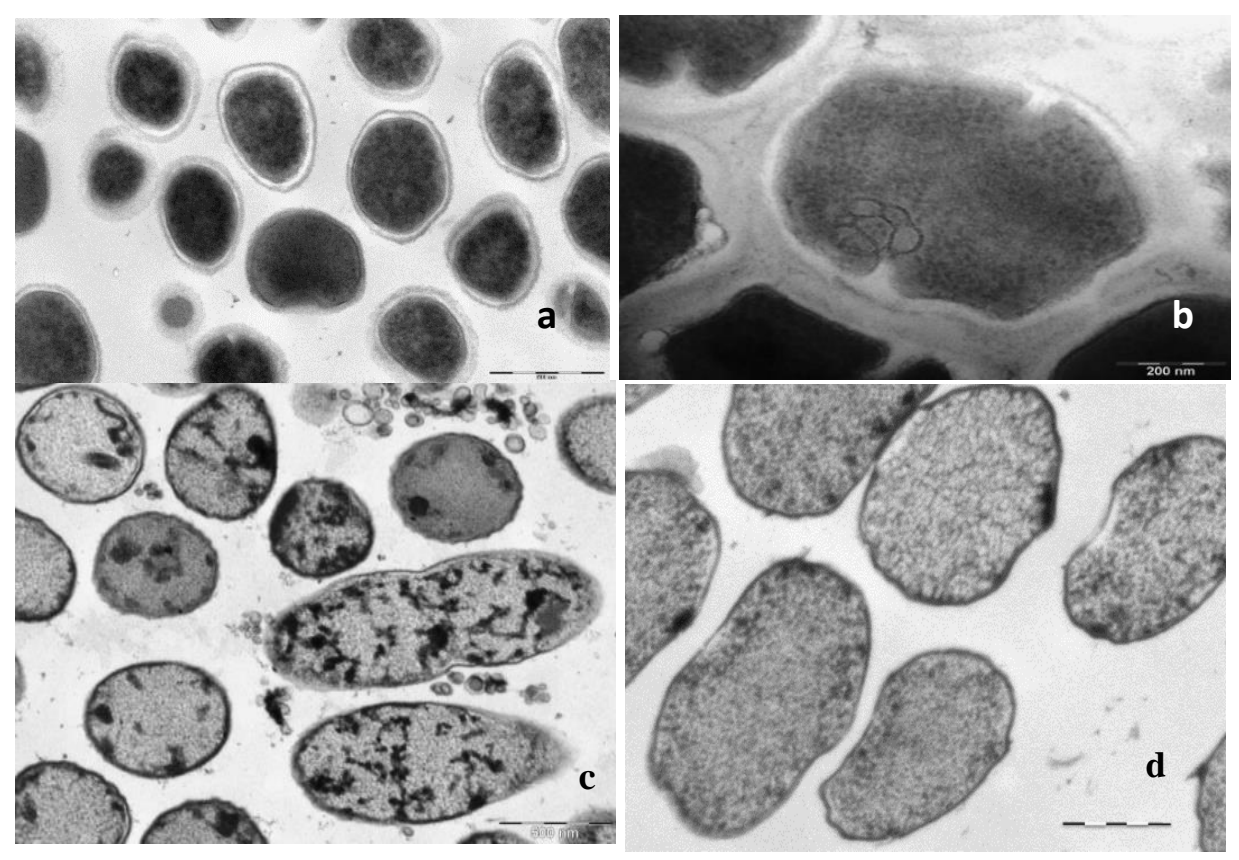

Figure 5 


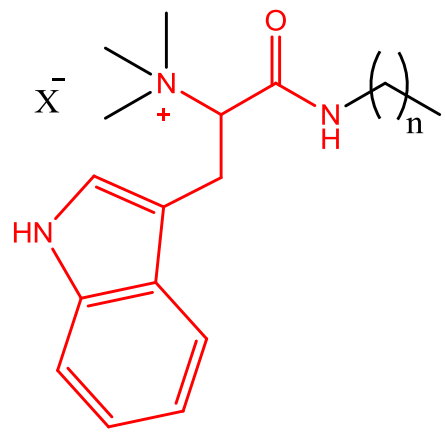

Series 15

Tryptophan based surfactants

$n=9,11,13,15,17$

For $n=15 \mathrm{X}=$ Clhoride, hexanoate, phenyl acetate

and naphthalene acetate<smiles>CN(C)C(Cc1ccc(O[Al])cc1)C(=O)NC(C)(C)C</smiles>

16

Tyrosine based surfactants

Figure 6 


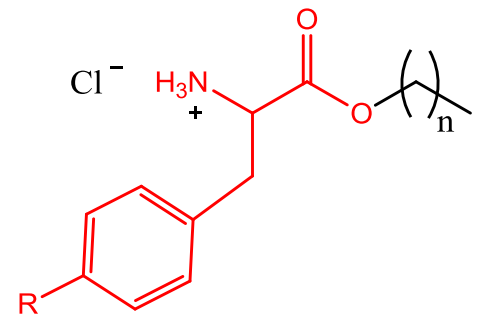

Series 17

$R=H$, Phenylalanine derivatives $(n=0,1,2,3,7,9,11,13,15,17,19)$

$\mathrm{R}=\mathrm{OH}$, Tyrosine derivatives $(n=7,9,11,13)$

\section{Figure 7}


<smiles>[R2]C(=O)C([R])NC(=O)C(CCCNC(=N)Cl)NC(=O)C1(C)CCC1(C)C</smiles>

Series 18

$\mathrm{R}^{\prime}=\mathrm{CH}_{3}$, cationic surfactants

LAGOM ( $\mathrm{R}=\mathrm{H}$, glycine), LAPOM $\mathrm{R}=\mathrm{CH}_{2}-\mathrm{C}_{6} \mathrm{H}_{5}$, phenylalanine LALM $(\mathrm{R}=(\mathrm{CH} 2) 4-\mathrm{NH} 3$, Lysine

$\mathrm{R}^{\prime}=\mathrm{OH}$, amphoteric surfactants

LAGOH ( $\mathrm{R}=\mathrm{H}$, glycine), LAPOH $\left(\mathrm{R}=\mathrm{CH}_{2}-\mathrm{C}_{6} \mathrm{H}_{5}\right.$, phenylalanine

LALOH $\left(\mathrm{R}=\left(\mathrm{CH}_{2}\right)_{4}-\mathrm{NH}_{3}\right.$ Lysine $)$ LAGuOM $\left(\mathrm{R}=\left(\mathrm{CH}_{2}\right)_{2}-\mathrm{COOH}\right.$

Glutamic acid)

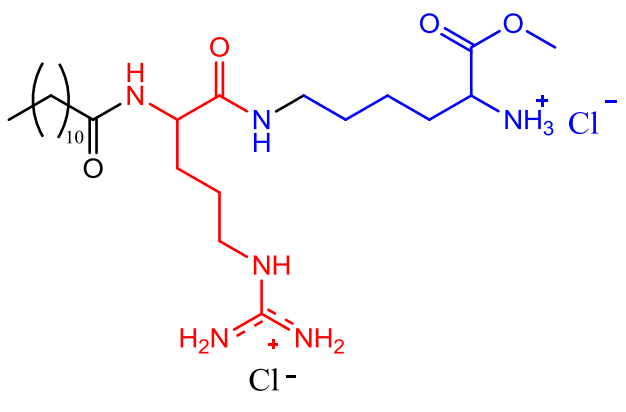

20

AKM

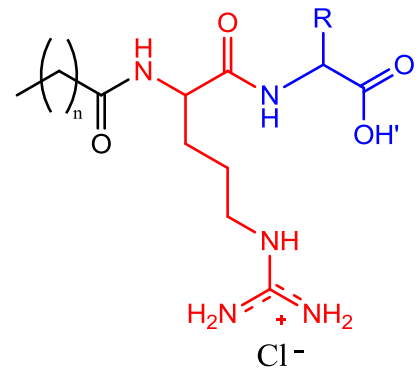

$\mathrm{C}_{8} \mathrm{AC}-\mathrm{C}_{16} \mathrm{AC}$

$\mathrm{R}=$ residue of amino acid coming from collagen $\mathrm{n}=6,8,10,12,14$

\section{Series 21}

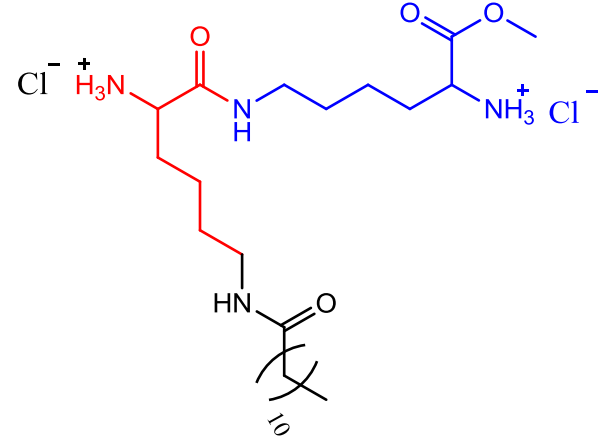

19

LKKM

Figure 8. 


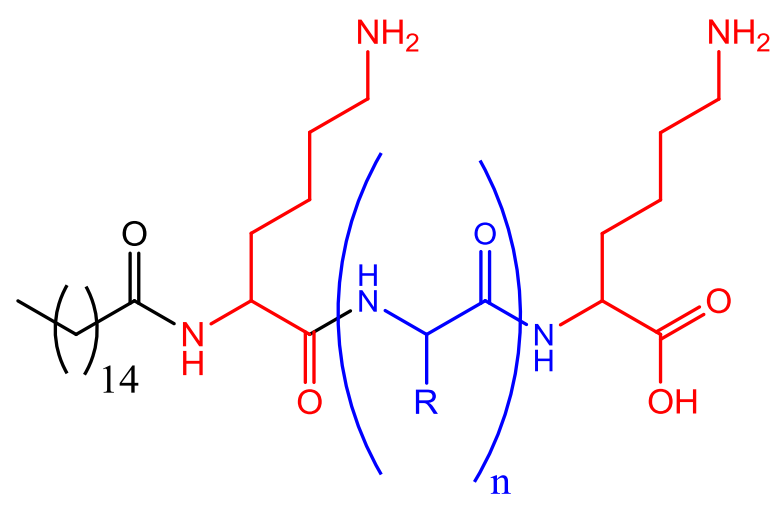

Series 22

Figure 9 


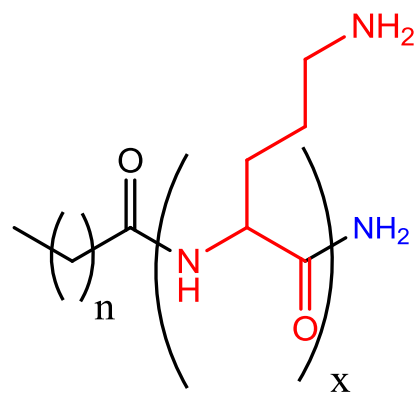

Series 23

Ex=123.4.5

$n=6,8,10,12,14,16$

Figure 10 


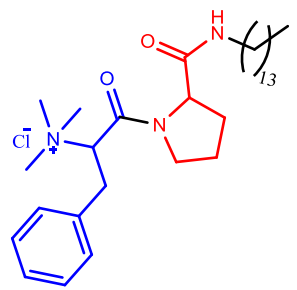

24

PheProl- $\mathrm{C}_{14}$

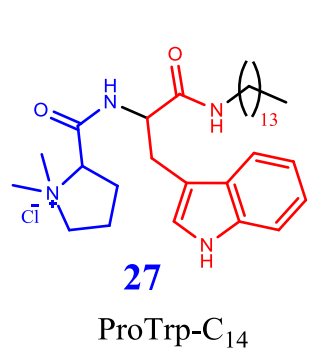

ProTrp-C 14

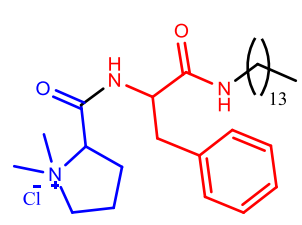

25

ProPhe- $\mathrm{C}_{14}$

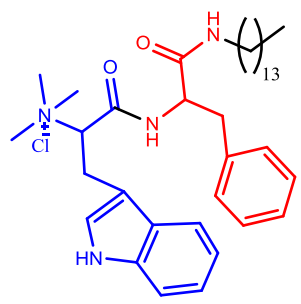

28

TrpPhe- $\mathrm{C}_{14}$

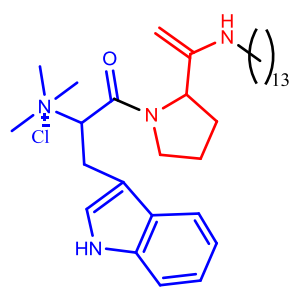

26

TrpProl- $\mathrm{C}_{14}$

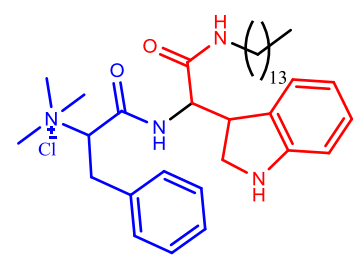

29

PheTrp- $\mathrm{C}_{14}$
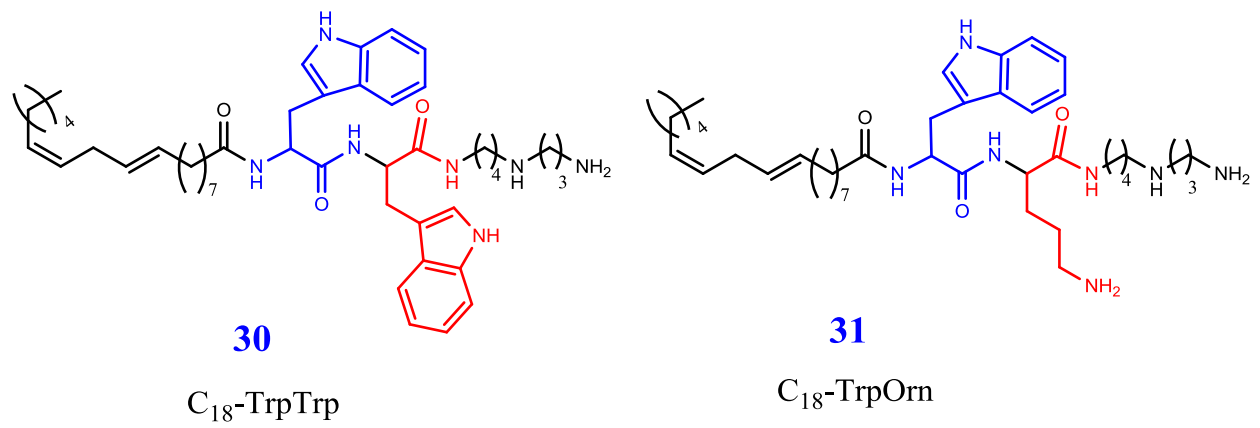

31

$$
\mathrm{C}_{18} \text {-TrpOrn }
$$

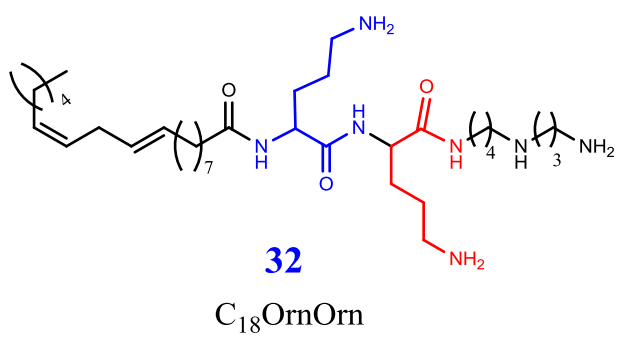

Figure 11

68 


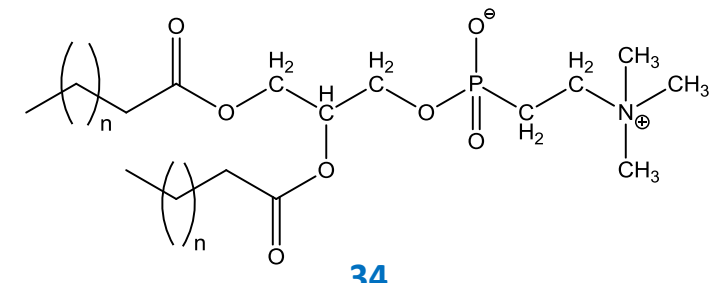

34

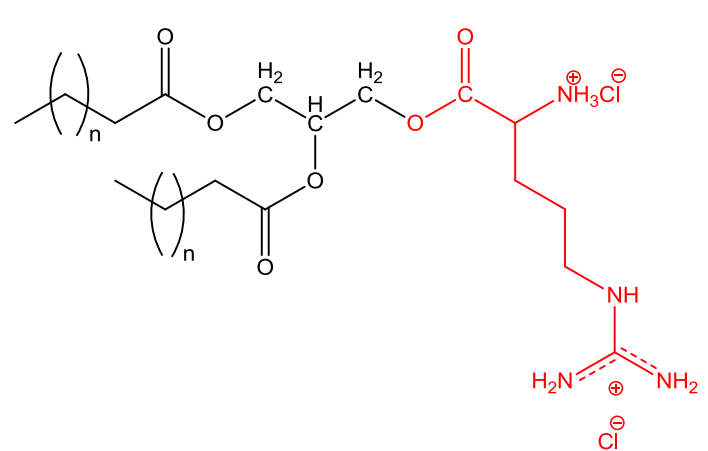

Series 35

XXR

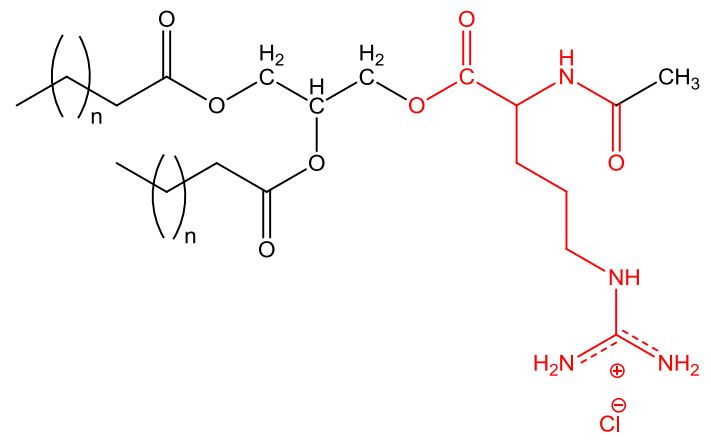

Series 36

XXRAC

Figure 12 


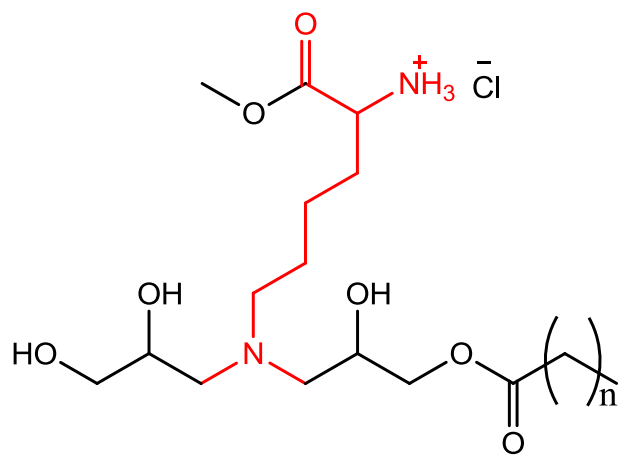

$$
\begin{gathered}
n=10 \text { LGG12 } \\
n=12 \text { LGG14 } \\
\text { Series } 37
\end{gathered}
$$

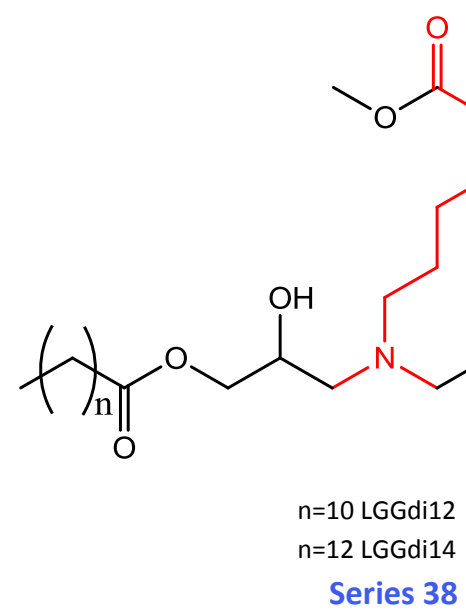<smiles>COC(=O)C([NH3+])CCCCN(CC(O)COC(=O)C(C)(C)C)CC(COC(=O)C(C)(C)C)OC(=O)C(C)(C)C(C)(C)C</smiles>

$$
\begin{array}{r}
\mathrm{n}=10 \text { LGGtri12 } \\
\mathrm{n}=12 \text { LGGtri14 } \\
\text { Series } 39
\end{array}
$$

Figure 13 


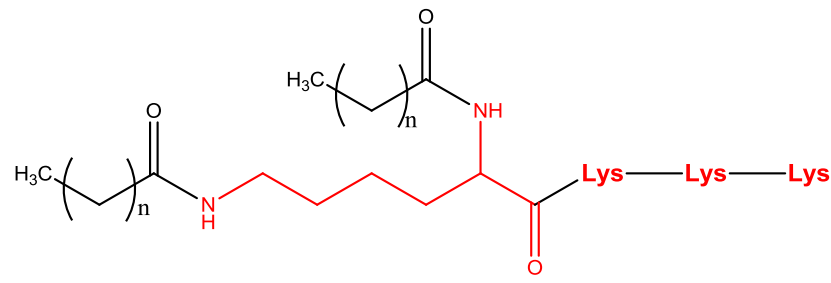

Series 40

$\mathrm{n}=7,\left(\mathrm{C}_{8}\right)_{2}-\mathrm{KKKK}-\mathrm{NH}_{2}$

$\mathrm{n}=9,\left(\mathrm{C}_{10}\right)_{2}-\mathrm{KKKK}-\mathrm{NH}_{2}$

$\mathrm{n}=11,\left(\mathrm{C}_{12}\right)_{2}-\mathrm{KKKK}-\mathrm{NH}_{2}$

$\mathrm{n}=14,\left(\mathrm{C}_{14}\right)_{2}-\mathrm{KKKK}-\mathrm{NH}_{2}$

Figure 14 


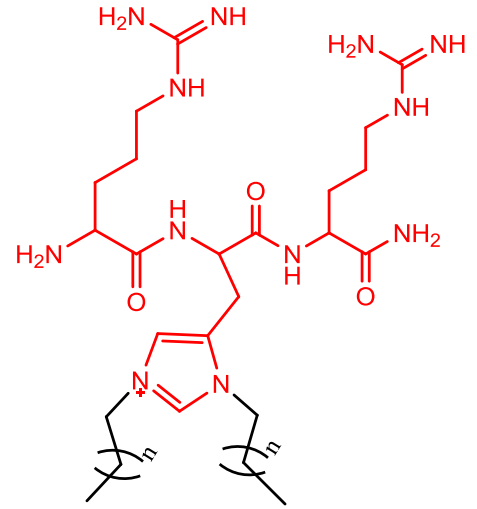

Series 41a

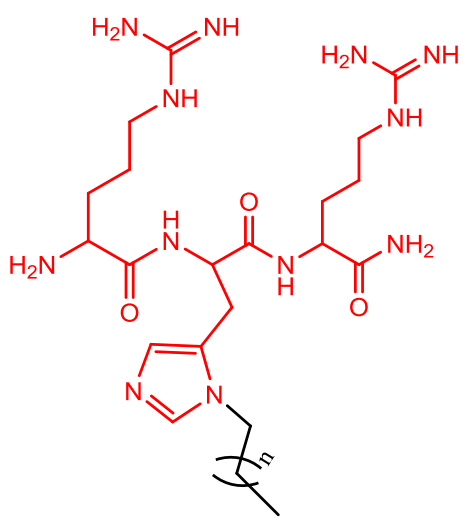

Series 41b

Figure 15 


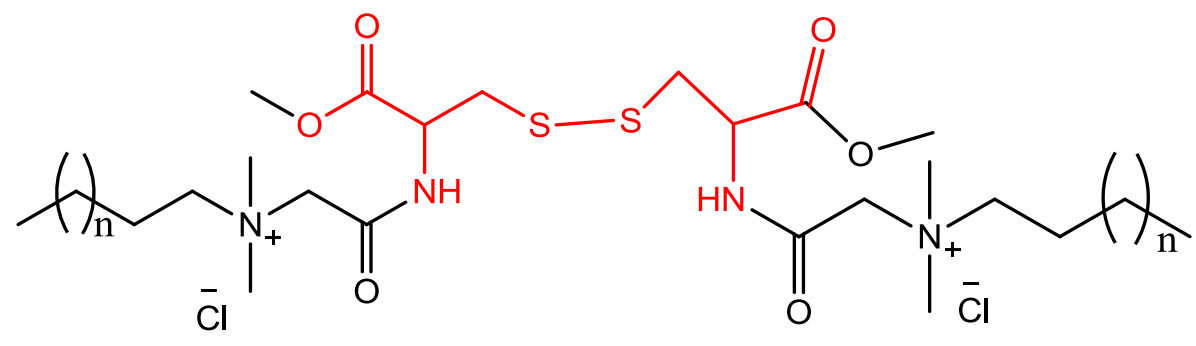

42

Figure 16 


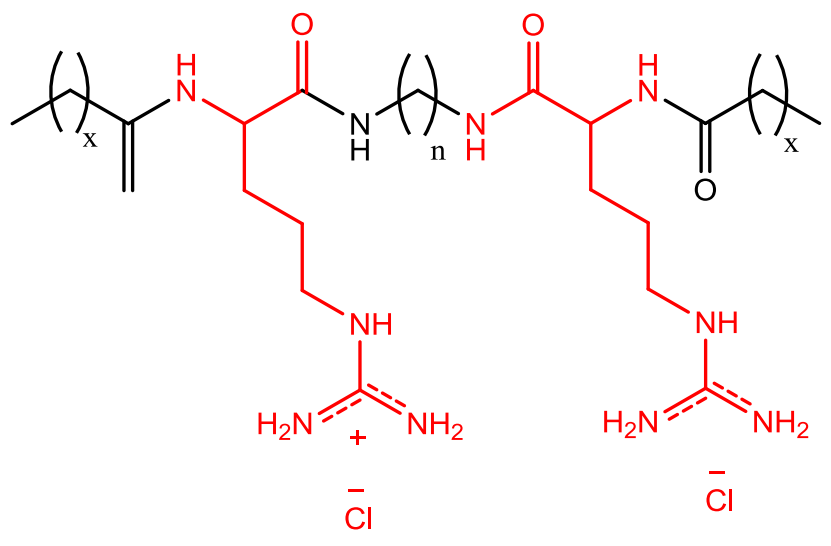

Series 43

$\mathrm{X}=10 ; \mathrm{C}_{\mathrm{n}}(\mathrm{LA})_{2}$

$X=8 ; C_{n}(C A)_{2}$

$X=6 ; C_{n}(O A)_{2}$

$\mathrm{N}=$ number of carbón atoms in the spacer chain

Figure 17 


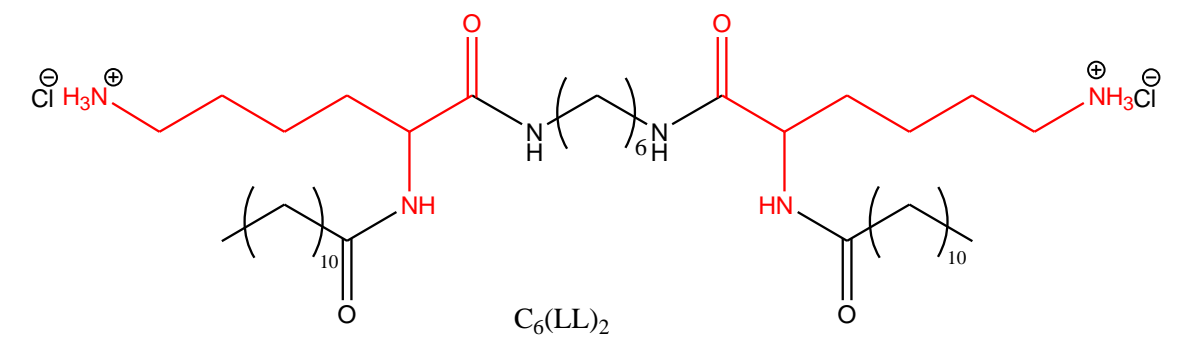

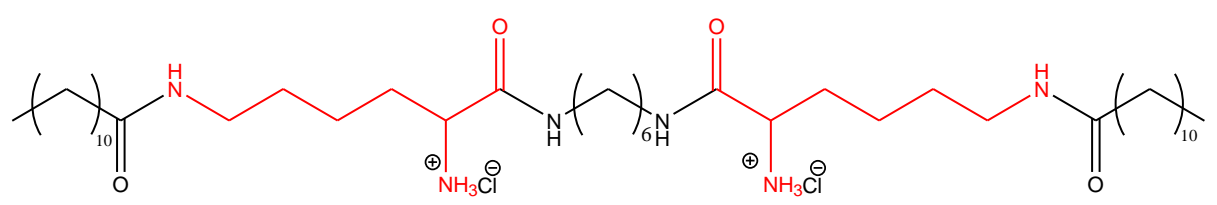

$\mathrm{C}_{6}(\mathrm{LK})_{2}$

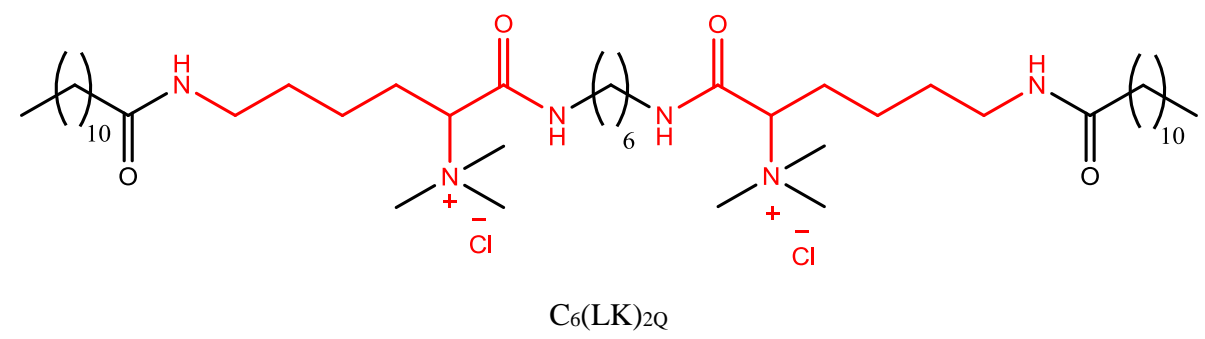

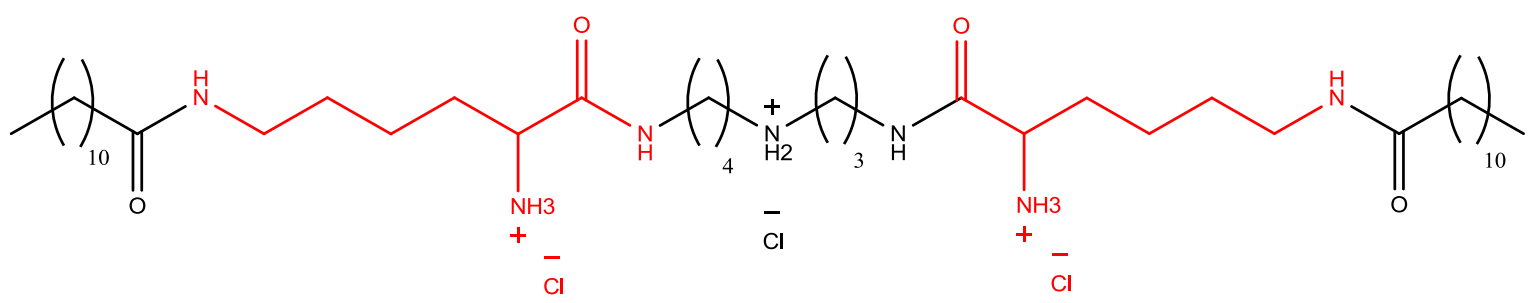

$\mathrm{C}_{6} \mathrm{NH}(\mathrm{LK})_{2}$

Series 44

Figure 18 


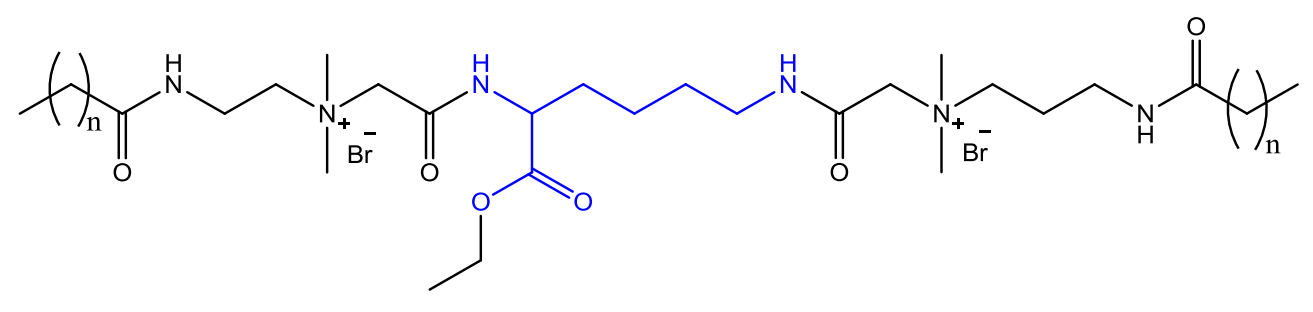

Series 45

Figure 19 


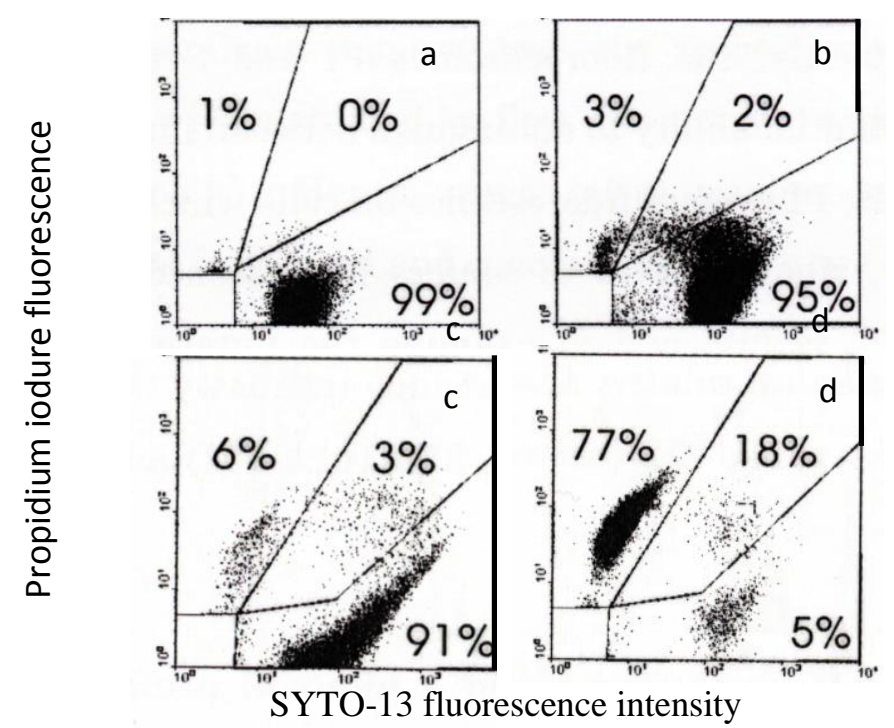

Figure 20 


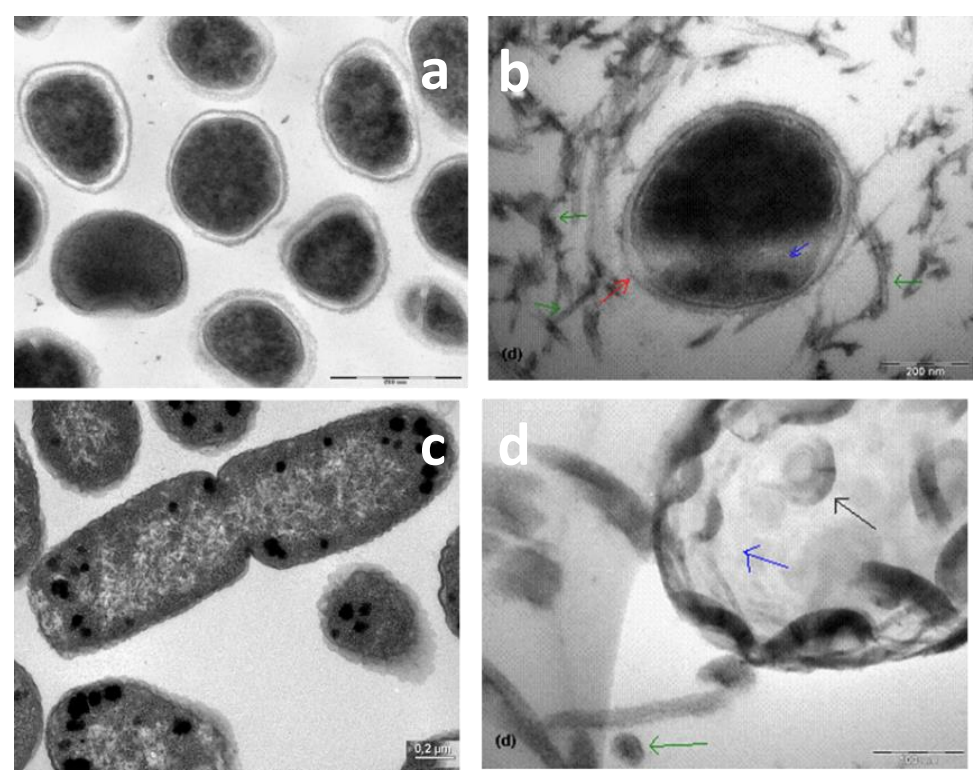

Figure 21 

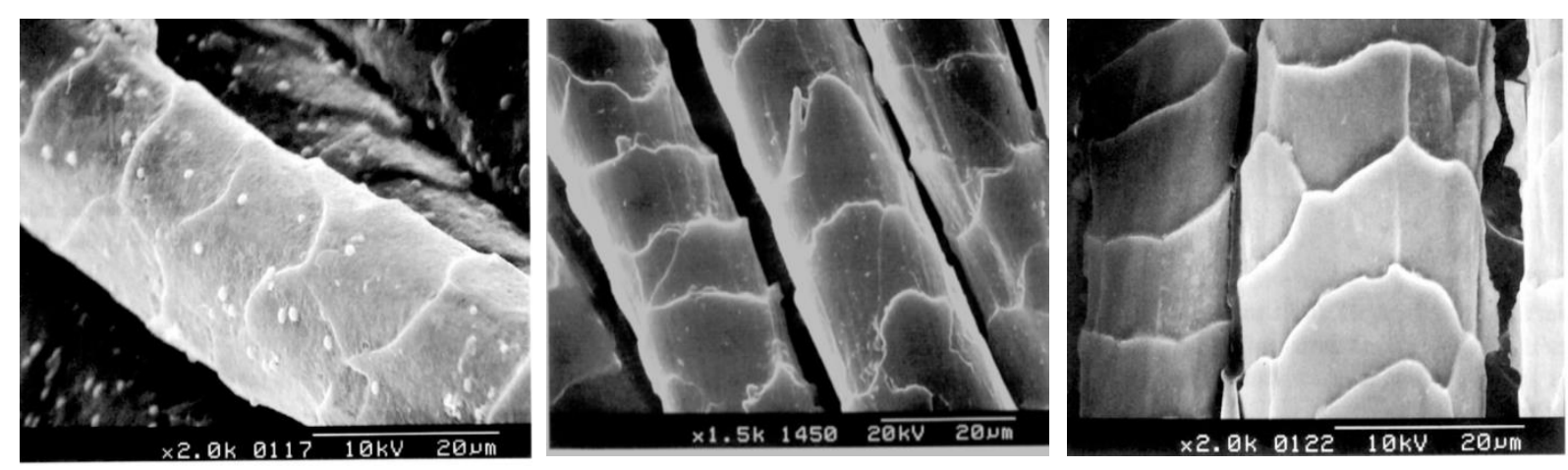

Figure 22 
